\title{
Linking Global Changes of Snowfall and Wet-Bulb Temperature
}

\author{
SAgAR K. TAMANG AND ARDEShIR M. EbTEHAJ \\ Saint Anthony Falls Laboratory and Department of Civil, Environmental and Geo-Engineering,
} University of Minnesota-Twin Cities, Minneapolis, Minnesota

ANDreas F. PREIN AND ANDREW J. HEYMSFIELD

National Center for Atmospheric Research, Boulder, Colorado

(Manuscript received 4 April 2019, in final form 20 August 2019)

\begin{abstract}
Snowfall is one of the primary drivers of the global cryosphere and is declining in many regions of the world with widespread hydrological and ecological consequences. Previous studies have shown that the probability of snowfall occurrence is well described by wet-bulb temperatures below $1^{\circ} \mathrm{C}\left(1.1^{\circ} \mathrm{C}\right)$ over land (ocean). Using this relationship, wet-bulb temperatures from three reanalysis products as well as multisatellite and reanalysis precipitation data are analyzed from 1979 to 2017 to study changes in potential snowfall areas, snowfall-torainfall transition latitude, snowfall amount, and snowfall-to-precipitation ratio (SPR). Results are presented at hemispheric scales, as well as for three Köppen-Geiger climate classes and four major mountainous regions including the Alps, the western United States, High Mountain Asia (HMA), and the Andes. In all reanalysis products, while changes in the wet-bulb temperature over the Southern Hemisphere are mostly insignificant, significant positive trends are observed over the Northern Hemisphere (NH). Significant reductions are observed in annual-mean potential snowfall areas over $\mathrm{NH}$ land (ocean) by $0.52(0.34)$ million $\mathrm{km}^{2} \mathrm{decade}^{-1}$ due to an increase of $0.34^{\circ} \mathrm{C}\left(0.35^{\circ} \mathrm{C}\right)$ decade $^{-1}$ in wet-bulb temperature. The fastest retreat in $\mathrm{NH}$ transition latitudes is observed over Europe and central Asia at $0.7^{\circ}$ and $0.45^{\circ}$ decade $^{-1}$. Among mountainous regions, the largest decline in potential snowfall areas is observed over the Alps at $3.64 \%$ decade $^{-1}$ followed by the western United States at $2.81 \%$ and HMA at $1.85 \%$ decade $^{-1}$. This maximum decrease over the Alps is associated with significant reductions in annual snowfall of $20 \mathrm{~mm} \mathrm{decade}^{-1}$ and SPR of $2 \%$ decade $^{-1}$.
\end{abstract}

\section{Introduction}

Snow and its meltwater play a crucial role in the global water and energy cycle. Snowpack stores freshwater in winter and releases it during the summer when it is needed the most (Viviroli et al. 2007; Wan et al. 2014). In a warmer world, a lower proportion of winter precipitation falls as snow and winter snowpack melts earlier in spring, causing water shortages in summer (Barnett et al. 2005). Climate projections indicate that a population of almost 2 billion people could be exposed to a high risk of decreased snow water supply in the next century (Mankin et al. 2015). Multidecadal observations show that snow-cover areal extent has declined significantly over the Northern Hemisphere (NH) (Brown and Robinson 2011; Hori et al. 2017). There are also regional studies indicating declines of important snowpack reservoirs around the globe at different rates (Rauscher

Corresponding author: Sagar K. Tamang, taman011@umn.edu et al. 2008; Ashfaq et al. 2013; Marty et al. 2017; Mote et al. 2018).

Snowfall accumulation controls the mass balance of snowpack and glaciers. The changes of snowfall are largely due to competing effects of changes in precipitation, air temperature, and moisture content. Increased global temperature and specific humidity are expected to alter the spatial distribution and intensity of global precipitation (Willett et al. 2007). As the air temperature increases, the water holding capacity of air also increases, which could give rise to more precipitation. However, the snowfall-to-precipitation ratio might decrease, especially over areas where the air temperature changes seasonally around the freezing point. Regional studies report that the snowfall is decreasing over important mountainous regions of the world, including the Himalayas (Gusain et al. 2014; Mir et al. 2015), the Tibetan Plateau (Wang et al. 2016), the Italian Alps (Valt and Paola 2013), the Rockies and Sierra Nevada (Howat and Tulaczyk 2005; Knowles 
et al. 2006; Feng and $\mathrm{Hu}$ 2007), and the Tian Shan (Guo and $\mathrm{Li} \mathrm{2015).} \mathrm{It} \mathrm{is} \mathrm{also} \mathrm{reported} \mathrm{that} \mathrm{over} \mathrm{the} \mathrm{Arctic,}$ snowfall has declined, largely due to decreasing total precipitation and increasing lower-atmospheric temperature (Screen and Simmonds 2012).

Despite significant progress in the understanding of regional changes in snowfall, there is still a large gap in our knowledge about the global changes in snowfall space-time distribution. Satellite precipitation data are promising to help close this gap in cold climate regions, which typically have sparse ground observations. However, unlike rainfall (Bolvin et al. 2009; Huffman et al. 2009; Behrangi et al. 2016), a sufficiently long and reliable record of satellite snowfall is still lacking. The recently launched Global Precipitation Measurement (GPM; 2014-present) satellite (Hou et al. 2014; Skofronick-Jackson et al. 2017) will reduce this gap over the years to come, but its observation record is still too short. Multisensor precipitation products such as the Tropical Rainfall Measurement Mission (TRMM) Multi-Satellite Precipitation Analysis (TMPA; Huffman and Bolvin 2013) and Pentad Global Precipitation Climatology Project (GPCP) (Xie et al. 2003) provide records of cumulative precipitation obtained from a combination of rain gauges and retrievals from a series of spaceborne sensors. However, these products currently do not have any specific information on precipitation phase.

The phase of precipitation can be inferred from the near-surface air temperature (Kienzle 2008; Dai 2008), dewpoint temperature (Marks et al. 2013), or wet-bulb temperature (Ding et al. 2014; Sims and Liu 2015; Zhong et al. 2018). The energy budget of falling hydrometeors is affected by atmospheric humidity (Harpold et al. 2017) and thus the wet-bulb temperature, which accounts for the effects of the air moisture content, can better capture the phase of precipitation than the air temperature (Harder and Pomeroy 2013; Ding et al. 2014). Sims and Liu (2015) studied the uncertainty range defined as the difference between the 10th and 90th percentiles of the snowfall conditional probability using 9700 stations over global land and oceans from 1950 to 2007 . They found that the uncertainty range is narrower for the wet-bulb temperature than the air temperature both over land $\left(2.5^{\circ}\right.$ vs $\left.3.3^{\circ} \mathrm{C}\right)$ and oceans $\left(3.6^{\circ}\right.$ vs $\left.5.0^{\circ} \mathrm{C}\right)$. Their results show that precipitation is in solid form with more than $50 \%$ probability when the near-surface wet-bulb temperature is below $1{ }^{\circ} \mathrm{C}$ over land and $1.1^{\circ} \mathrm{C}$ over oceans. More recently, Jennings et al. (2018) also showed improved precipitation phase detection by the methods that incorporate air humidity than those solely relying on air temperature, particularly at a relative humidity below saturation and air temperatures between $0.6^{\circ}$ and $3.4^{\circ} \mathrm{C}$.

The objective of this paper is to enhance our understanding of the global changes in potential snowfall areas, the position of the rainfall-to-snowfall transition latitudes, total snowfall amount (defined as snow water equivalent), and the snowfall-to-precipitation ratio (SPR) in the past few decades. The paper focuses on changes over the Köppen-Geiger (Peel et al. 2007) Arid cold, cold, and polar climate classes as well as four important mountainous regions of the world: the Alps, the western United States including the Rockies and Sierra Nevada, High Mountain Asia (HMA), and the Andes. For the analyses, we use observational and reanalysis precipitation estimates and 2-m wet-bulb temperature processed from multiple reanalysis datasets. To improve the inference, reanalysis data of wet-bulb temperatures are merged and the computed SPR values are validated, using the wet-bulb temperature and SPR derived from ground-based gauge observations by the National Climatic Data Center [NCDC; now known as the National Centers for Environmental Information (NCEI)].

The paper is organized as follows: Section 2 discusses the datasets and preprocessing tasks. The key measure of changes and a summary of the used statistical approaches for trend identification are described in section 3 . Section 4 demonstrates and interprets the results while section 5 concludes and discusses findings and its implications. Computation of the wet-bulb temperature using the approach by Stull (2016), statistical trend analysis, and the quality metrics used in the validation parts are explained in the appendixes.

\section{Data and preprocessing}

\section{a. Wet-bulb temperature}

We use the latest generation of three reanalysis products, from credible meteorological agencies in Europe, Asia, and the United States, to process and characterize the global changes of the wet-bulb temperature. These reanalysis products include the European Centre for Medium-Range Weather Forecasts (ECMWF) interim reanalysis (ERA-Interim) (Dee et al. 2011), the Japanese 55-yr Reanalysis (JRA-55) (Kobayashi et al. 2015), and the NCEP-DOE R-2 (Kanamitsu et al. 2002) by the United States National Centers for Environmental Prediction (NCEP) and Department of Energy (DOE). These reanalysis products provide the required information for calculating wet-bulb temperature from 1979 to the present every $6 \mathrm{~h}$, at spatial grid resolutions of $0.125^{\circ}, 0.5625^{\circ}$, and $2.5^{\circ}$, respectively. 


\section{b. Precipitation}

Uncertainty in global estimates of precipitation can be large, particularly in regions with low station density and snow-dominated environments (Sun et al. 2018). Satellite-based precipitation datasets are expected to provide improved estimates of the global precipitation and enhance the accuracy of the reanalysis products. However, passive microwave satellite data are not free of error, especially over complex topography where the microwave signal of shallow precipitation is weak (Ebtehaj et al. 2016). For example, intercomparison studies over Europe have shown that satellite products have a tendency to overestimate precipitation over flat regions and underestimate it over mountainous regions (Prein and Gobiet 2017). Sun et al. (2018) compared annual precipitation estimates from multiple sources with 70000 gauge station data obtained from the Global Precipitation Climatology Center (GPCC). It is shown that gauge-corrected satellite estimates of precipitation such as GPCP perform better than the reanalysis products such as ERA-Interim, JRA-55, and NCEP-DOE R-2. Here we use a multisensor observational precipitation dataset in combination with reanalysis precipitation from the ERA-Interim to estimate the robustness of our results.

For observational precipitation data, we use the Pentad GPCP, version 2.2, which provides multisensor estimates of 5-day surface global precipitation at a spatial resolution of $2.5^{\circ}$ from 1979 to 2016 (Xie et al. 2003, 2011). This product is created by merging the Pentad Climate Prediction Center (CPC) Merged Analysis of Precipitation (CMAP) (Xie and Arkin 1997) and the GPCP monthly multisensor precipitation product (Adler et al. 2003). The Pentad CMAP dataset optimally combines gauge precipitation data from more than 6000 Global Telecommunication System (GTS) stations, NCEP-NCAR reanalysis precipitation (Kalnay et al. 1996), and precipitation estimates from the infrared sensor on board the Geostationary Operational Environmental Satellite (GOES), the Microwave Sounding Unit on the Television Infrared Observation Satellite (TIROS), the Special Sensor Microwave Imager (SSM/I) on board the Defense Meteorological Satellite Program (DMSP) satellites, and the Advanced Very High Resolution Radiometer (AVHRR) on board the National Oceanic and Atmospheric Administration (NOAA) operational sunsynchronous polar-orbiting satellites. In accordance to the GPCP policy of avoiding numerical model influence, the observation-only version of the Pentad CMAP $(\mathrm{CMAP} / \mathrm{O})$ was utilized in the production of Pentad GPCP.

\section{c. Gauge data}

We used gauge data (2011-15) from the NCDC Global Surface Summary of the Day (GSOD; Lott 1998; Smith et al. 2011) for error analysis of the wet-bulb temperatures and validation of SPR. Gauge observations of air temperature, dewpoint temperature, pressure, precipitation amount, and indicator of its type (fog, rain, snow, or hail) were obtained for calculating the wet-bulb temperature and SPR. 3579 NCDC stations with $\sim 4.1$ million station days (data from one station in one day) were used (Fig. 1), while only 803 station years could be utilized for annual validation of the SPR. The reason is that all stations with more than 10 days $\mathrm{yr}^{-1}$ of missing information on precipitation amount and phase were not utilized. Furthermore, to avoid any inflation of validation statistics due to lower SPR values, any station years with $<0.01 \mathrm{SPR}$ values were removed. It should be noted that NCDC data are among a large suite of satellite and ground-based observations that are assimilated into the used reanalysis products and merged into the GPCP data. However, due to model and representative errors and the differences between the used data assimilation techniques, this does not necessarily imply that the reanalysis errors with respect to the gauge data are zero or strongly correlated.

\section{Methodology}

\section{a. Reanalysis ensemble mean}

Multiple reanalysis data can be considered as an ensemble realization of the underlying variable of interest and can be integrated for reducing the uncertainty of inference (Hagedorn et al. 2005; Solman and Orlanski 2016). In this study, we use the maximum likelihood (ML) estimator of the reanalysis products. To that end, we assume that the 2-m wet-bulb temperature $T_{\mathrm{wb}}^{t, m}$ by reanalysis product $m$ at time $t$ is related to the ground truth wet-bulb temperature $T_{\mathrm{wb}}^{t}$ as follows:

$$
T_{\mathrm{wb}}^{t, m}=T_{\mathrm{wb}}^{t}+\varepsilon_{m}, \quad \varepsilon_{m} \sim \mathscr{N}\left(0, \sigma_{m}^{2}\right),
$$

where the reanalysis error $\varepsilon_{m}$ are uncorrelated zeromean normally distributed random variables with variance $\sigma_{m}^{2}$. Therefore, the likelihood function can be obtained as $\mathscr{L}\left(T_{\mathrm{wb}}^{t, m} \mid T_{\mathrm{wb}}^{t}\right) \propto \Pi_{m=1}^{3} \exp \left[-\left(T_{\mathrm{wb}}^{t, m}-T_{\mathrm{wb}}^{t}\right)^{2} / 2 \sigma_{m}^{2}\right]$ for which the ML estimate of the reanalysis wet-bulb temperature $\hat{T}_{\mathrm{wb}}^{t}$ is as follows:

$$
\hat{T}_{\mathrm{wb}}^{t}=\underset{T_{\mathrm{wb}}^{t}}{\arg \min } \sum_{m=1}^{3} \frac{\left(T_{\mathrm{wb}}^{t, m}-T_{\mathrm{wb}}^{t}\right)^{2}}{\sigma_{m}^{2}},
$$

which can be simplified as 
(a)

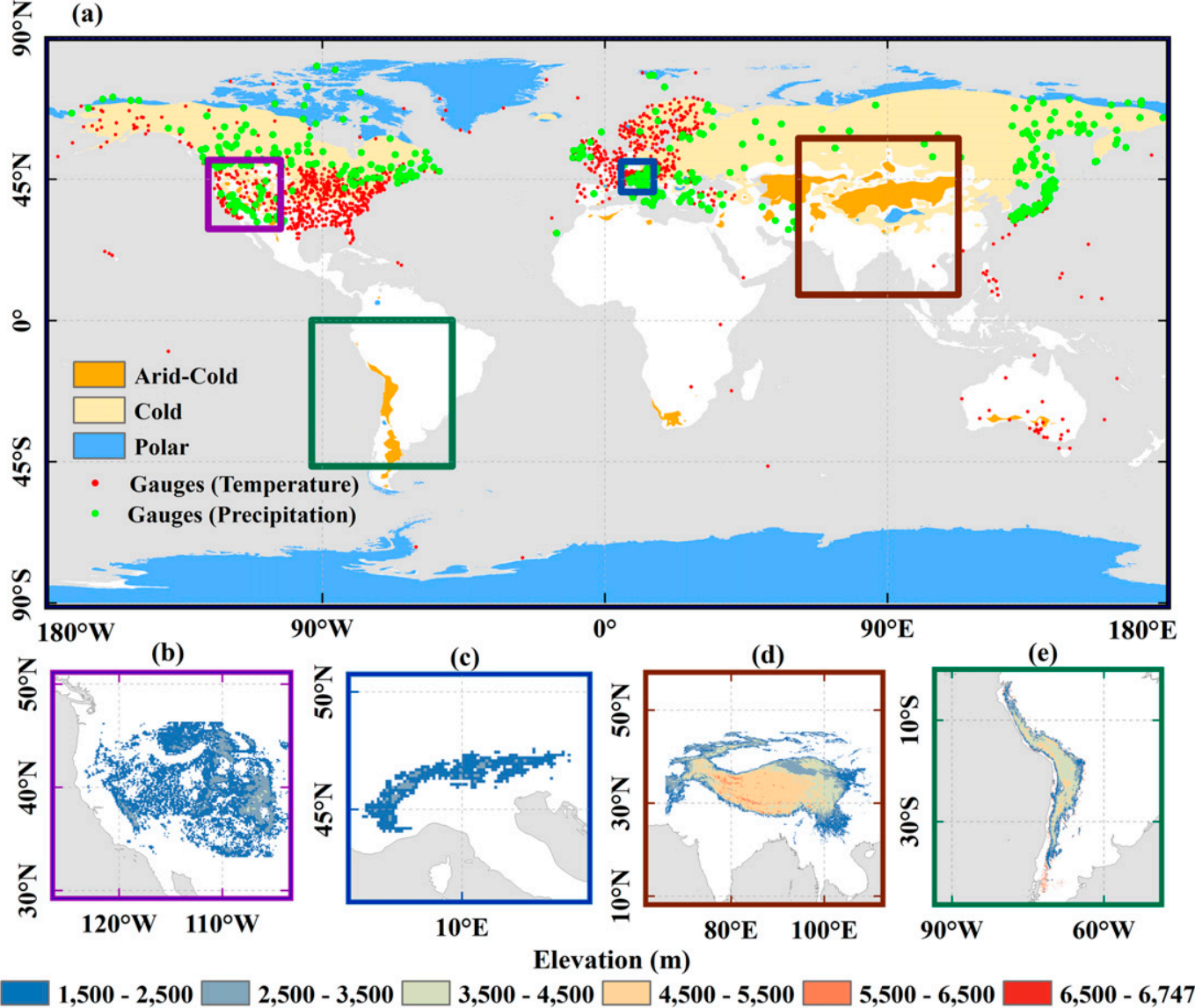

FIG. 1. (a) Location of the NCDC gauge stations used in the study for error analysis of the reanalysis-based wetbulb temperature and validation of SPR from 2011 to 2015. The map shows three Köppen-Geiger climate classes including the arid cold (orange), cold (yellow), and polar (blue). Also shown are the elevation maps, from the NOAA digital elevation model at 1-km resolution, which determine the boundaries for the mountainous regions of (b) the western United States, (c) the Alps, (d) HMA, and (e) the Andes (Blyth et al. 2002).

$$
\hat{T}_{\mathrm{wb}}^{t}=\sum_{m=1}^{3} w_{m} T_{\mathrm{wb}}^{t, m}
$$

where $w_{m}=\sigma_{m}^{-2}\left(\sum_{m} \sigma_{m}^{-2}\right)^{-1}$ and the variance of the ML estimator is given by $\left(\sum_{m} \sigma_{m}^{-2}\right)^{-1}$. Because of the Gaussian assumption, the ML estimate is equivalent to an ensemble mean that is weighted based on the inverse of the error variance of each reanalysis product. In the above formalism, we assumed that the reanalysis data are unbiased, which is a reasonable assumption as will be shown later.

\section{b. Potential snowfall area}

Denoting the wet-bulb temperature at a pixel-level $(i, j)$ as $T_{\mathrm{wb}}(i, j)$, the potential snowfall area is defined as the interior area of the set $\mathscr{S}$ of all global pixels over which $T_{\mathrm{wb}}(i, j) \leq T_{\mathrm{wb}}^{s}$. Here, $T_{\mathrm{wb}}^{s}$ denotes snowfall threshold of $1^{\circ} \mathrm{C}$ over land and $1.1^{\circ} \mathrm{C}$ over oceans (Sims and Liu 2015), which defines the boundaries $\partial \mathscr{S}$ of the set. Throughout, we use daily wet-bulb temperature from reanalysis datasets and their ensemble mean to first compute daily potential snowfall area and then infer its seasonal and annual changes.

\section{c. Snowfall-to-rainfall transition latitudes}

The analysis of the potential snowfall areas provides a bulk quantitative indication on how areal extent of global snowfall is shrinking or expanding over time. However, another key question is this: Where, and to what extent, is the global snowfall changing into rainfall? The location and movement of the boundary of potential snowfall areas capture the regions that are experiencing the most significant interannual variability of snowpack water storage and related hydrologic response. As explained before, this freezing boundary $\partial \mathscr{S}$, can be defined as the contour of $T_{\mathrm{wb}}^{s}$ that separates potential snowfall and rainfall areas. To that end, we define the snowfall-to-rainfall transition latitudes as the 
boundary of the potential snowfall areas with a prespecified decadal exceedance probability. For example, latitudes with $25 \%$ exceedance probability represent the boundary of the areas within which the snow can fall at least $25 \%$ of the days over a decade. This decadal representation is used to capture the long-term trends and cancel out the short-term interannual variabilities.

\section{d. Total snowfall and snowfall-to-precipitation ratio}

As previously noted, we also study the changes of total snowfall and snowfall-to-precipitation ratio (SPR) not only for the Pentad GPCP but also for ERA-Interim. We combine the ensemble-mean reanalysis wet-bulb temperature with the Pentad GPCP precipitation to compute the SPR. To that end, the ensemble mean of reanalysis wet-bulb temperatures is computed daily at the spatial resolution of ERA-Interim, that is, $0.125^{\circ}$; however, cumulative Pentad GPCP precipitation is available every 5 days at a spatial resolution of $2.5^{\circ}$. Therefore, the Pentad GPCP data are first mapped onto the grids of the ensemble mean through the nearestneighbor interpolation to avoid any loss or addition of spurious information. The relative frequency of snowfall occurrence for each pixel is defined as a fraction of the number of days when the daily wet-bulb temperature is below the snowfall threshold in 5 days. The computed relative frequency is then multiplied with precipitation amount to obtain an estimate of snowfall amount. Annual SPR is finally obtained by dividing the cumulative snowfall amount by the annual cumulative precipitation amount as follows:

$$
\operatorname{SPR}(i, j)=\frac{\sum_{t=1}^{n_{p}} f_{s}^{t}(i, j) P(i, j)}{P(i, j)},
$$

where the relative frequency of snowfall occurrence is $f_{s}^{t}(i, j)=(1 / T) \sum_{t=1}^{T} 1_{\mathscr{S}}\left[T_{\mathrm{wb}}^{t}(i, j)\right], 1_{\mathscr{S}}\left[T_{\mathrm{wb}}^{t}(i, j)\right]$ is an indicator function that is equal to 1 if $T_{\mathrm{wb}}^{t}(i, j) \leq T_{\mathrm{wb}}^{s}$ and 0 otherwise, $P(i, j)$ represents the pixel-level cumulative precipitation during the Pentad GPCP temporal resolution, $T=5$ denotes the number of days in a pentad period, and $n_{p}$ is the number of 5-day precipitation data points per year.

Precipitation and snowfall from the ERA-Interim are obtained from the 12-hourly accumulated totals. The values are then summed up for the entire year to provide the annual precipitation and snowfall as the snow water equivalent. Then the annual SPR is finally obtained by dividing the annual snowfall by the annual precipitation amount.

\section{e. Trend analysis}

We use the nonparametric Theil-Sen method (Theil 1950; Sen 1968) for computing the magnitude of linear trends. The Theil-Sen method computes the trend by taking the median of the slopes of all possible lines that are fitted to pairs of sample points. This method does not require any parametric assumption about the probability distribution of the samples and exhibits higher degree of accuracy than the ordinary least squares (OLS), in the presence of heteroscedasticity (Wilcox 2010). Additionally, since this approach relies on the median of the slopes, the estimated trends are more robust to observational outliers than the OLS, which approximates the mean value of the trends (Matoušek et al. 1998; Wilcox 2010).

Numerous tests have been examined to quantify the statistical significance of the Theil-Sen estimator such as the parametric $t$ test (Student 1908) and nonparametric Mann-Kendall (MK) test (Mann 1945; Kendall 1948). Here we adopt the bootstrap MK test (BS-MK; Douglas et al. 2000) as Yue and Pilon (2004) showed that this method has a higher probability of correct rejection of the null hypothesis for linear trend detection of nonGaussian data structure, among other commonly used tests.

The asymptotic null distribution of the MK test statistic is valid under the assumption of serial independence (von Storch 1995). To formally account for the effects of serial dependence, prewhitening (von Storch 1995) and trend-free prewhitening (Yue et al. 2002) approaches have been proposed. Yue and Wang (2004) showed that the presence of positive (negative) serial correlation in the data inflates (deflates) the variance of MK test statistic and thus proposed a variancecorrection method. Additionally, block bootstrap approaches (Kundzewicz and Robson 2000; Önöz and Bayazit 2012) have been suggested to approximate directly the null distribution of the MK test statistic through resampling, without removing the serial dependence of the data. Khaliq et al. (2009) compared the performance of the explained methods and found that the prewhitening methods are conservative in identifying significant trends while both variance correction and block bootstrap methods perform well for dependent time series.

The variants of the block bootstrap method (Kunsch 1989; Carlstein 1986; Kunsch 1989; Liu and Singh 1992; Politis and Romano 1994) are an extension to the original bootstrap inference approach (Efron 1979) for approximating the sample distribution of a statistic in serially dependent datasets. This method reconstructs the bootstrap samples through resampling of data blocks beyond which the dependent structure of the data becomes negligible. Here, we confine our consideration to the classic moving-block bootstrap (MBB; Liu and Singh 1992), which has been applied and tested 
(a) ERA - Interim
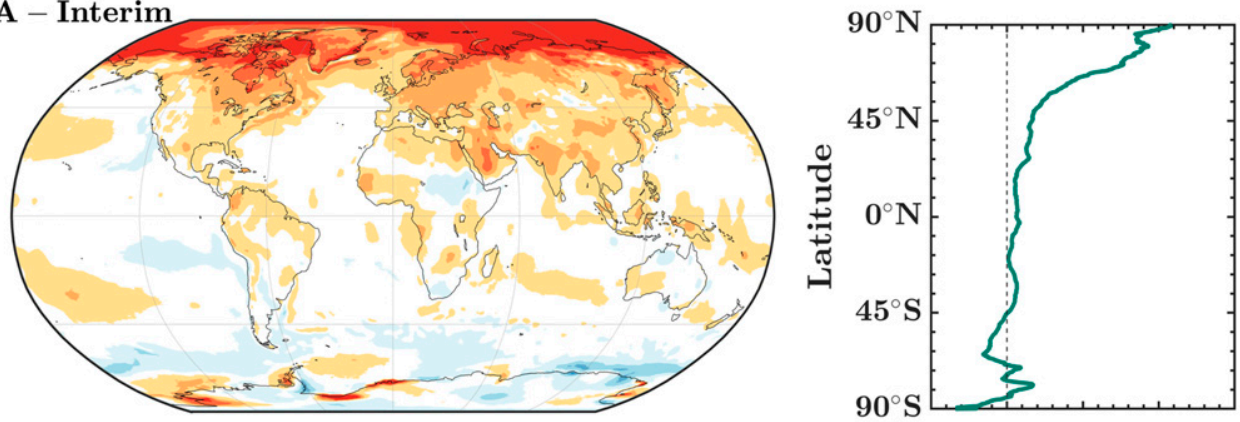

(b) JRA - 55
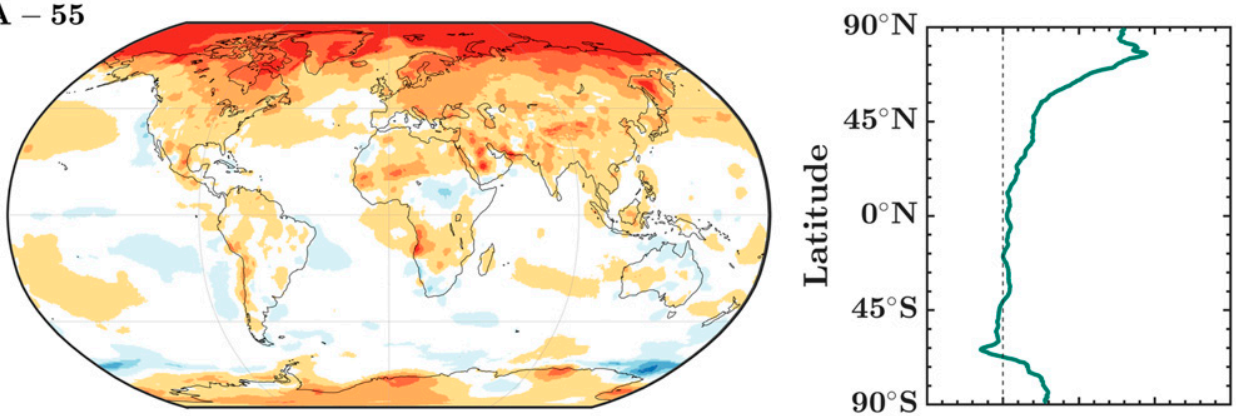

(c) NCEP - DOE
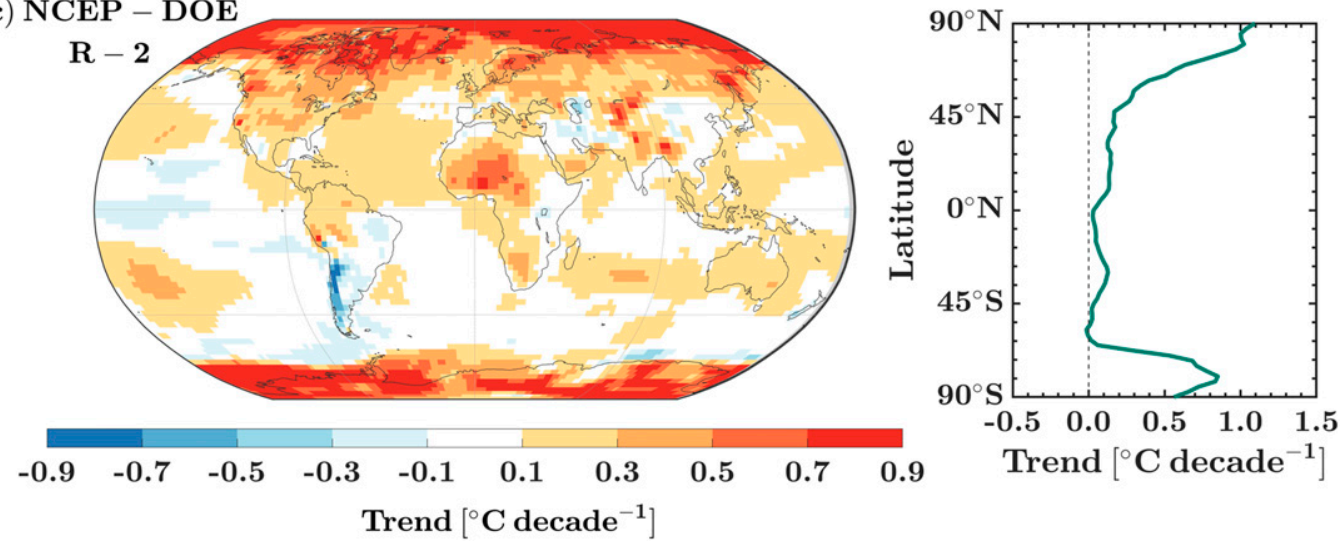

FIG. 2. (left) Trends of annual-mean wet-bulb temperature and (right) its zonal mean for the reanalysis products from 1979 to 2017.

successfully for significance analysis of the MK estimates of linear trends (Khaliq et al. 2009; Önöz and Bayazit 2012).

Throughout, the trends at significance level $\alpha$ are reported as $\beta_{\alpha}\left(\beta_{\min }-\beta_{\max }\right)$, where $\beta_{\alpha}$ denotes the trend of the ensemble mean and values in parentheses denote the minimum and maximum of trends by the three reanalysis products. The reported changes without a subscript are insignificant at $\alpha=0.05$.

\section{Results}

In this section we present the results on changes of the wet-bulb temperatures among all reanalysis products and highlight their areas of discrepancy and agreement.
Then, we present the spatial trends in the mean ensemble wet-bulb temperature over the areas where the majority of the reanalysis products (i.e., 2 out of 3 ) agree. Focusing on the ensemble mean, the changes of the potential snowfall areas, transition latitudes, total snowfall, and snowfall-to-precipitation ratios are quantified and discussed.

\section{a. Changes in wet-bulb temperature}

Figure 2 shows the trends in annual-mean wet-bulb temperature (left) and its zonal mean (right) during the study period. Over the $\mathrm{NH}$, there is a good agreement between the three datasets, especially with respect to the detected positive trends over cold and polar climate regimes above the Arctic Circle. In particular, large 
(a) ERA-Interim

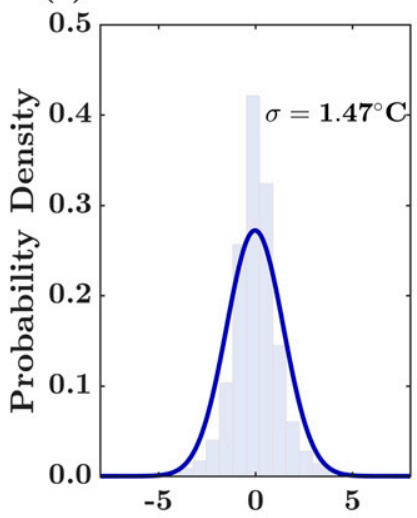

(b)

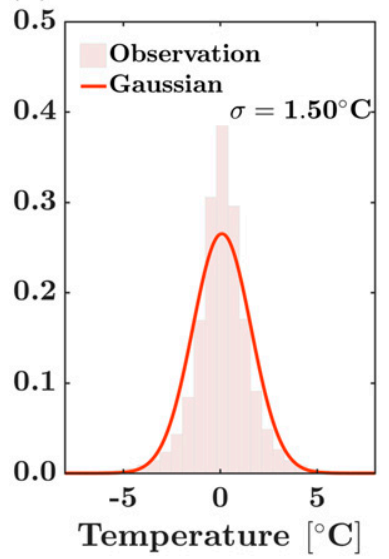

(c) NCEP-DOE R-2

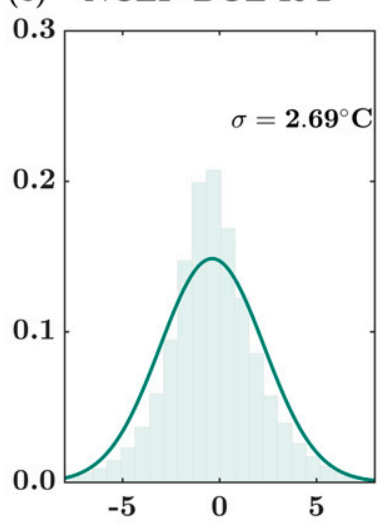

(d)

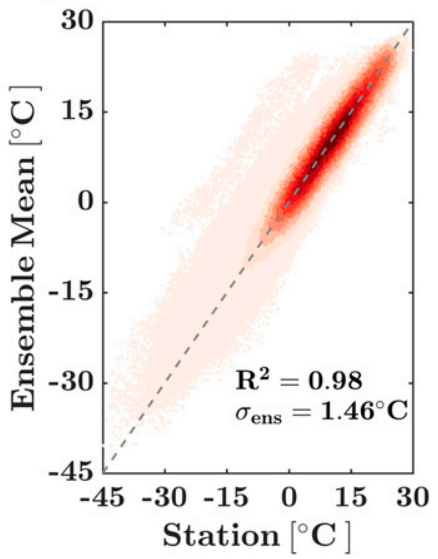

FIG. 3. Probability histogram of error in wet-bulb temperatures from (a) ERA-Interim, (b) JRA-55, and (c) NCEP-DOE R-2 as well as (d) the scatter density plot of their ensemble mean vs the NCDC GSOD gauge stations. The errors are computed by comparing the reanalysis and gauge station data from 2011 to 2015.

areas of Canada's tundra and boreal forests, the U.S. Midwest, the Greenland Ice Sheet, northern Europe, the central Siberian Plateau, and the Scandinavian peninsula have experienced a warming trend above $0.3^{\circ} \mathrm{Cdecade}^{-1}$. Some disagreements between the reanalysis products can be observed in lower latitudes, especially over the Iranian Plateau, Indian peninsula, and East Asia, where only ERA-Interim and JRA-55 indicate a coherent warming trend. The disagreement is more apparent over western Africa and across the North Atlantic Ocean, where only NCEP-DOE R-2 shows a coherent warming trend. Over higher latitudes $\left(70^{\circ}-\right.$ $90^{\circ} \mathrm{N}$ ), zonal-mean trends are consistently positive and larger than $0.5^{\circ} \mathrm{Cdecade}^{-1}$ in all three reanalysis products (Fig. 2, right column).

Over the $\mathrm{SH}$, there is large disagreement between the reanalysis datasets. The NCEP-DOE R-2 data indicate that the annual-mean wet-bulb temperature is decreasing coherently over the Andes and increasing over Australia, whereas these trends are not apparent in other reanalysis products. The disagreement is most pronounced over Antarctica where ERA-Interim does not show any spatially organized trend while a positive trend is seen in the other datasets, especially in NCEPDOE R-2. This warming trend is more significant and reaches more than $0.6^{\circ} \mathrm{Cdecade}^{-1}$ over Antarctica with a peak of around $0.85^{\circ} \mathrm{C}$ around $80^{\circ} \mathrm{S}$.

\section{b. Ensemble-mean wet-bulb temperature}

As previously explained, we use ground-based gauge stations from 2011 to 2015 to compute the ensemblemean wet-bulb temperature and validate some of the results. The error distribution of the reanalysis wet-bulb temperatures is shown in Figs. 3a-c. The reanalysis data are almost unbiased with respect to the areas that are densely populated by the gauges. Fitted Gaussian distributions have standard deviations of $1.47^{\circ}, 1.5^{\circ}$, and $2.69^{\circ} \mathrm{C}$ for ERA-Interim, JRA-55, and NCEP-DOE R-2, respectively. As shown in Fig. 3d, the ensemble-mean wet-bulb temperature compares well with the gauge data as the coefficient of determination $R^{2}$ reaches 0.98 and the ensemble-error standard deviation is reduced to $1.46^{\circ} \mathrm{C}$.

To better understand the spatial pattern of the trends, binary masks of significant warming and cooling trends $(\alpha=0.05)$ and insignificant trends are created for each reanalysis product and then overlaid (Fig. 4a) to identify the areas of agreement. The trend of the annual ensemblemean wet-bulb temperatures is computed and mapped onto the ERA-Interim $0.125^{\circ}$ grid, using nearest-neighbor interpolation, over the areas with majority agreement (Fig. 4b).

Over the NH lands, in all reanalysis products, positive trends are observed over the Arctic, the Midwest and northeastern United States, the European continent except the Iberian Peninsula, western Eurasia, the Tibetan highlands, and western China. The trends are around $0.8^{\circ} \mathrm{Cdecade}^{-1}$ over the Arctic and reduce to less than $0.4^{\circ} \mathrm{Cdecade}^{-1}$ over the midlatitudes and subtropical zones. Over the SH lands, areas of positive trends are less coherent. The majority of positive trends agree only over parts of Antarctica. Significant trends are observed over the Queen Maud Land and coasts of the Ross Dependency. It is important to note that the positive trends above $0.4^{\circ} \mathrm{Cdecade}^{-1}$ are concentrated over the Filchner, the Fimbulisen, and the Ross Ice Shelves.

The results in Fig. $4 c$ indicate that the changes are significant for all climate regimes except over the $\mathrm{SH}$ 

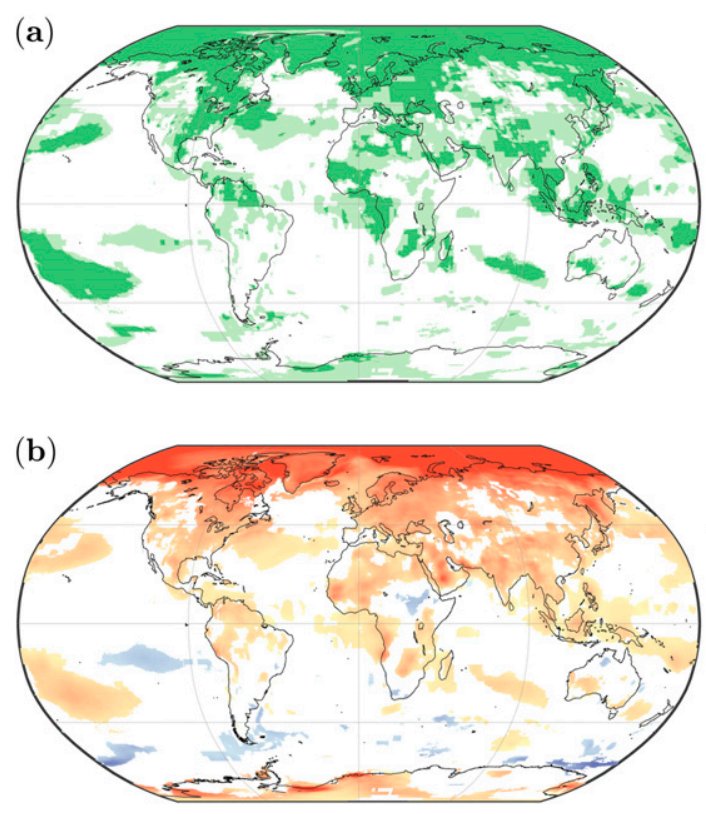

(d)

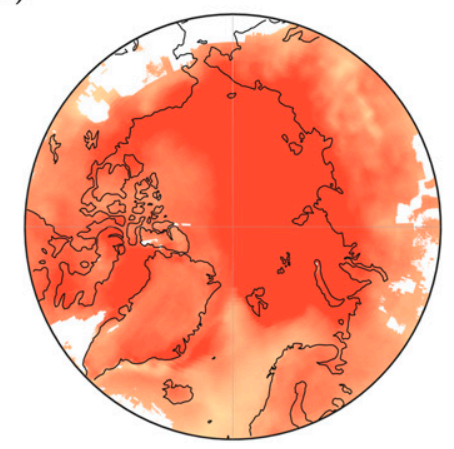

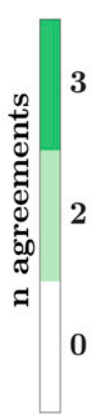

(c)

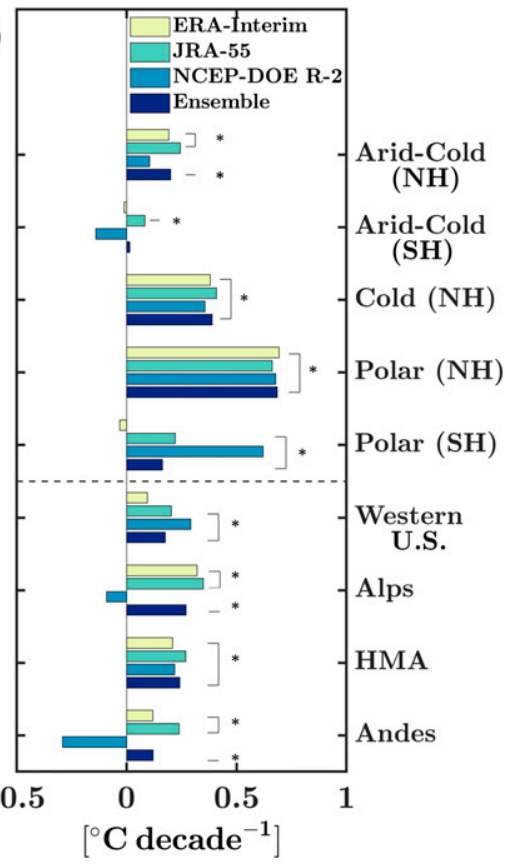

(e)

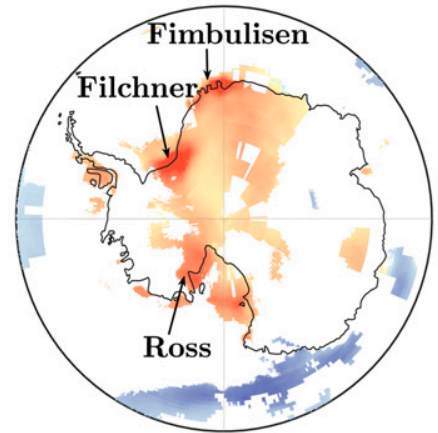

FIG. 4. (a) Spatial distribution of the agreement in significant trends $(\alpha=0.05)$ in the wet-bulb temperature between the three reanalysis products, (b) spatial distribution of the trends, and (c) the ensemble mean over the Köppen-Geiger climate classes and four mountain regions. In (c), significant trends are labeled by an asterisk. The trends are also shown in a polar projection system over (d) the Arctic and (e) Antarctica.

arid cold climates. Specifically, the ensemble mean shows the highest warming rate of $0.69_{0.05}(0.66-0.69)^{\circ} \mathrm{Cdecade}^{-1}$ (where the subscript indicates the statistical significance level) over the $\mathrm{NH}$ polar climate regime, followed by $\mathrm{NH}$ areas with cold and arid cold climates at $0.39_{0.01}(0.36-0.41)^{\circ} \mathrm{C} \mathrm{decade}^{-1}$ and $0.20_{0.01}(0.11-0.24)^{\circ} \mathrm{C}$ decade $^{-1}$, respectively. The majority of the reanalysis products indicate that there has been a warming trend over the studied mountainous regions, among which the Alps are experiencing the highest positive trend at $0.27_{0.01}(-0.09-0.35)^{\circ} \mathrm{C} \mathrm{decade}^{-1}$ followed by the HMA and the western United States at $0.24_{0.01}(0.21-$ $0.27)^{\circ} \mathrm{Cdecade}^{-1}$ and $0.18_{0.05}(0.10-0.29)^{\circ} \mathrm{C}$ decade $^{-1}$, respectively.
Figure 5 shows the time series of the $\mathrm{NH}$ and $\mathrm{SH}$ annual-mean wet-bulb temperatures over global land and oceans, while Table 1 reports the seasonal changes as well. All reanalysis products agree over the $\mathrm{NH}$ both in terms of the trends and their annual-mean values, whereas over the $\mathrm{SH}$ the results show large uncertainties. The highest mean wet-bulb temperature is observed in 2016 over the $\mathrm{NH}$, both over land and oceans among all reanalysis products, whereas there is not such an agreement in $\mathrm{SH}$. Trend analysis suggests that the NH annual ensemble-mean wet-bulb temperature is rising over land and oceans at $0.34_{0.01}(0.32-$ $0.35)^{\circ} \mathrm{Cdecade}^{-1}$ and $0.35_{0.01}(0.34-0.41)^{\circ} \mathrm{Cdecade}^{-1}$. Among all seasons, highest warming is observed during 
(a) NH Land

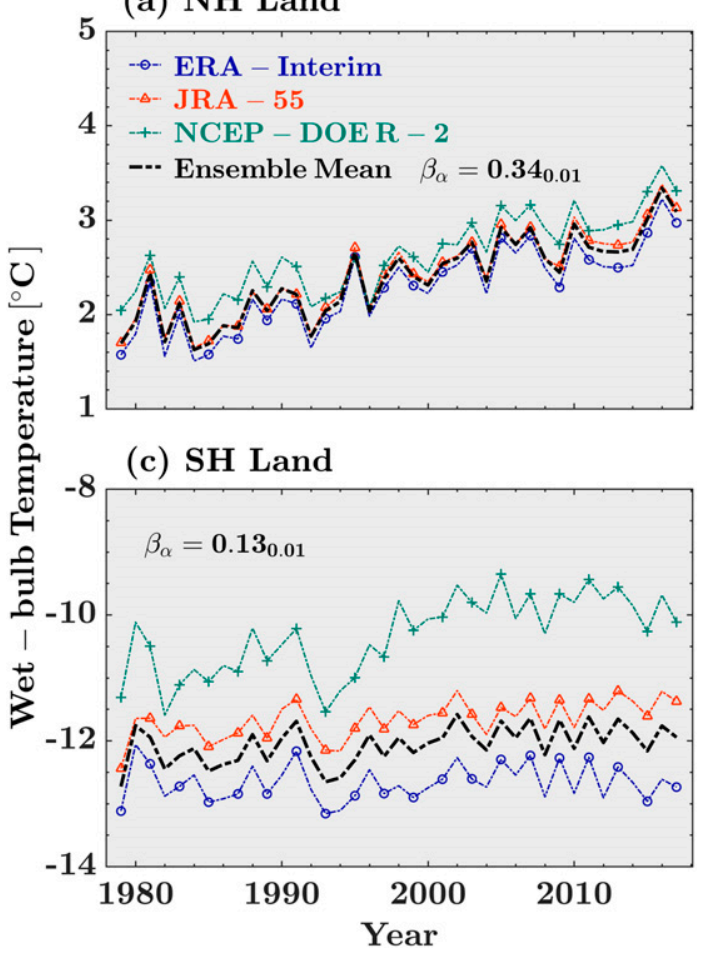

(b) NH Ocean

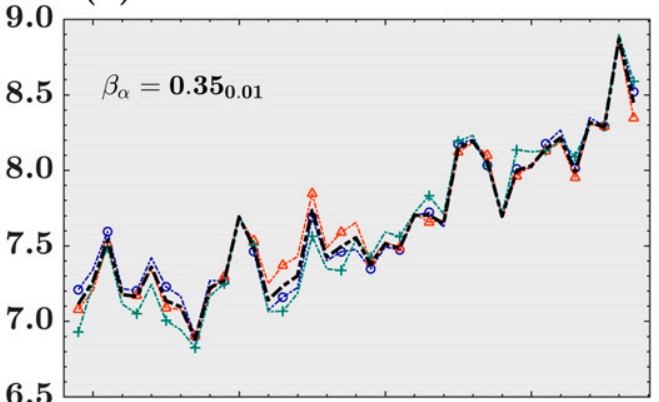

(d) SH Ocean

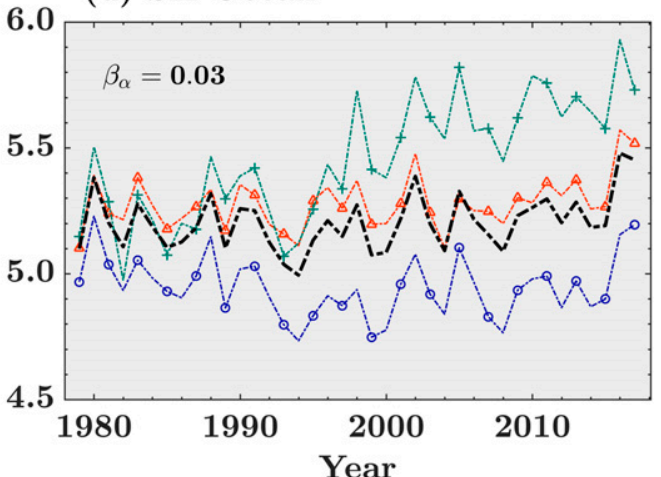

FIG. 5. Time series of annual-mean wet-bulb temperature for (a) NH land, (b) NH oceans, (c) SH land, and (d) SH oceans from 1979 to 2017 for the three reanalysis products and their ensemble mean. Here, $\beta_{\alpha}$ represents the trend value of the ensemble-mean wet-bulb temperature $\left({ }^{\circ} \mathrm{C} \mathrm{decade}{ }^{-1}\right)$ at significance level $\alpha$. Trend values without a subscript are insignificant.

the fall both over land at $0.37_{0.05}(0.35-0.38)^{\circ} \mathrm{Cdecade}^{-1}$ and oceans at $0.49_{0.05}(0.44-0.61)^{\circ} \mathrm{Cdecade}^{-1}$ (see Table 1).

Similar to the NH, annual-mean wet-bulb temperature over the $\mathrm{SH}$ is rising, but at a lower rate of $0.13_{0.01}(0.04$ $0.41)^{\circ} \mathrm{C}$ decade $^{-1}$ and $0.03(-0.02 \text { to } 0.16)^{\circ} \mathrm{C} \mathrm{decade}^{-1}$ over land and oceans, respectively. The SH spring manifests the highest warming rates over both over land and oceans with the rate of $0.26_{0.01}(0.15-0.56)^{\circ} \mathrm{Cdecade}^{-1}$ and $0.07_{0.01}(0.04-0.21)^{\circ} \mathrm{Cdecade}^{-1}$.

TABLE 1. Annual and seasonal changes of the hemispheric-mean wet-bulb temperature over the land and oceans. We define four seasons as winter (December-February), spring (March-May), summer (June-August), and fall (September-November) for the NH and winter (June-August), spring (September-November), summer (December-February), and fall (March-May) for the SH. Due to the absence of information during December 1978, the data over the NH winter (SH summer) were not analyzed in that year. The boldface values are significant at $\alpha=0.05$.

\begin{tabular}{|c|c|c|c|c|c|c|c|c|}
\hline \multirow[b]{2}{*}{ Seasons } & \multicolumn{2}{|c|}{ ERA-Interim } & \multicolumn{2}{|c|}{ JRA-55 } & \multicolumn{2}{|c|}{ NCEP-DOE R-2 } & \multicolumn{2}{|c|}{ Ensemble } \\
\hline & Land & Ocean & Land & Ocean & Land & Ocean & Land & Ocean \\
\hline \multicolumn{9}{|c|}{ Northern } \\
\hline Annual & +0.33 & +0.35 & +0.35 & +0.34 & +0.32 & +0.41 & +0.34 & +0.35 \\
\hline Winter & +0.23 & +0.51 & +0.26 & +0.44 & +0.24 & +0.49 & +0.25 & +0.47 \\
\hline Spring & +0.37 & +0.37 & +0.37 & +0.32 & +0.36 & +0.38 & +0.37 & +0.36 \\
\hline Summer & +0.25 & +0.12 & +0.28 & +0.14 & +0.24 & +0.16 & +0.26 & +0.14 \\
\hline Fall & +0.38 & +0.44 & +0.37 & +0.49 & +0.35 & +0.61 & +0.37 & +0.49 \\
\hline \multicolumn{9}{|c|}{ Southern } \\
\hline Annual & +0.04 & -0.02 & +0.15 & +0.03 & +0.41 & -0.16 & +0.13 & +0.03 \\
\hline Winter & +0.01 & +0.02 & +0.15 & +0.03 & +0.53 & +0.31 & +0.12 & +0.07 \\
\hline Spring & +0.15 & +0.04 & +0.29 & +0.06 & +0.56 & +0.21 & +0.26 & +0.07 \\
\hline Summer & -0.06 & -0.04 & +0.14 & +0.05 & +0.13 & -0.04 & +0.06 & +0.00 \\
\hline Fall & +0.01 & -0.06 & +0.11 & -0.02 & +0.33 & +0.17 & +0.09 & -0.01 \\
\hline
\end{tabular}


(a) NH Land

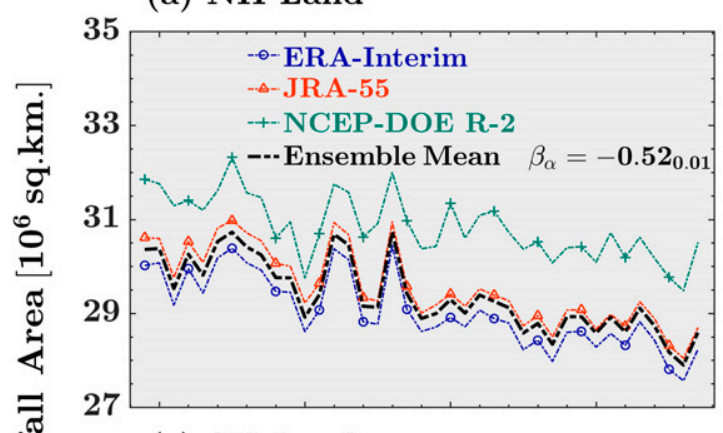

(c) SH Land

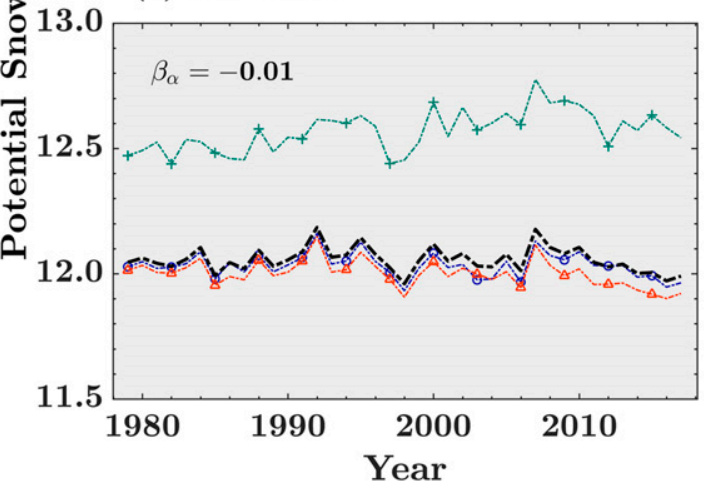

(b) NH Ocean

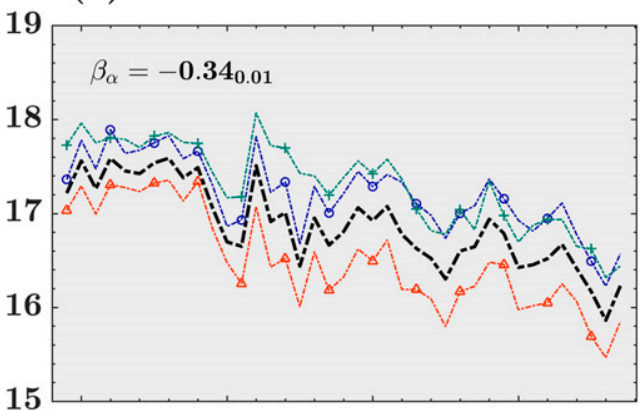

(d) SH Ocean

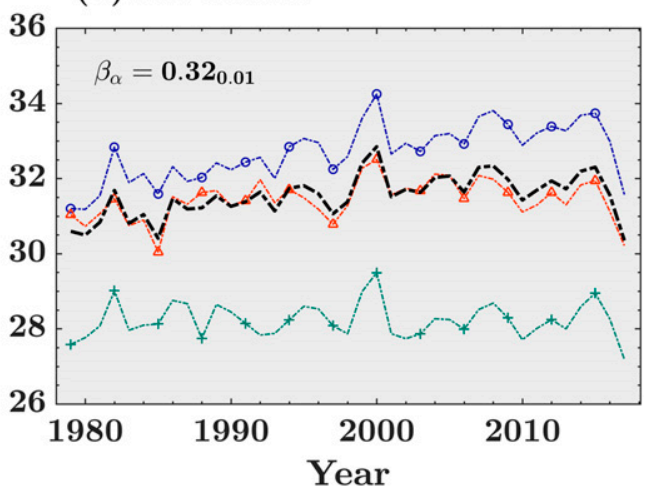

FIG. 6. Time series of the annual-mean potential snowfall areas for (a) NH land, (b) NH oceans, (c) SH land, and (d) SH oceans from 1979 to 2017 for the three reanalysis products and their ensemble mean. The values of $\beta_{\alpha}$ represent the trend of the ensemble mean (million $\mathrm{km}^{2}$ decade $^{-1}$ ) at significance level $\alpha=0.05$ and the values without subscript are insignificant.

\section{c. Changes in potential snowfall areas}

The annual time series of the hemispheric-mean potential snowfall areas are shown in Fig. 6 and the seasonal values are reported in Table 2 as well. Over the $\mathrm{NH}$ land, annual-mean potential snowfall areas are decreasing at a rate of $0.52_{0.01}(0.44-0.56)$ million $\mathrm{km}^{2}$ decade $^{-1}$, which is more than over $\mathrm{NH}$ oceans: $0.34_{0.01}(0.28-0.39)$ million $\mathrm{km}^{2} \mathrm{decade}^{-1}$. Seasonal analysis suggests that the shrinkage rate is largest during the $\mathrm{NH}$ spring at $0.81_{0.01}$ (0.58-0.86) million $\mathrm{km}^{2} \mathrm{decade}^{-1}$ and fall at $0.44_{0.01}(0.41-$ $0.58)$ million $\mathrm{km}^{2}$ decade $^{-1}$ over the land and oceans, respectively.

However, the results over the $\mathrm{SH}$ are different. Over land, no significant reduction in annual-mean potential snowfall area is observed, whereas over oceans it has increased significantly at the rate of $0.32_{0.01}(0.03-$ 0.53) million $\mathrm{km}^{2}$ decade $^{-1}$-despite a detected increase in the mean wet-bulb temperature (Fig. 5). No significant seasonal changes are detected over the $\mathrm{SH}$ land (Table 2) whereas over the oceans all seasonal changes are significant, except winter. The highest shrinkage rate occurs during the summer at $0.55_{0.01}$ (0.31-0.70) million $\mathrm{km}^{2}$ decade $^{-1}$.
The contrasting nature of changes of potential $\mathrm{SH}$ snowfall areas and mean wet-bulb temperature exists due to the spatial heterogeneity of the temperature trend. Figure $4 \mathrm{~b}$ shows that the positive trend in mean wet-bulb temperature is largely due to warming of the subtropical regions in the southern Pacific, Atlantic, and Indian Oceans with no effect on the potential snowfall areas. Because the temperature is well above the snowfall threshold throughout the year. In fact, the increase of SH potential snowfall areas has occurred over the Southern Oceans within temperate and Arctic climate zones, where the mean wet-bulb temperature is decreasing.

Annual-mean potential snowfall areas are decreasing over all studied Köppen-Geiger climate classes and the four mountain regions. Among the three climate classes, the highest decrease is observed over the $\mathrm{NH}$ cold climate regime at the rate of $0.33_{0.05}(0.25-$ 0.34) million $\mathrm{km}^{2}$ decade $^{-1}$ followed by the polar and the arid cold climates at the rate of $0.06_{0.05}(0.06-0.07)$ million $\mathrm{km}^{2}$ decade $^{-1}$ and $0.05_{0.01}(0.03-0.06)$ million $\mathrm{km}^{2}$ decade $^{-1}$, respectively. On average, we have lost 0.02 million $\mathrm{km}^{2}$ decade $^{-1}$ of snowfall areas over the four mountainous regions. The largest decrease is observed 
TABLE 2. Annual and seasonal changes of hemispheric-mean potential snowfall areas (million $\mathrm{km}^{2} \mathrm{decade}^{-1}$ ). The values in parentheses represent percentage of changes per decade with respect to the mean values. The boldface values are significant at $\alpha=0.05$.

\begin{tabular}{|c|c|c|c|c|c|c|c|c|}
\hline \multirow[b]{2}{*}{ Seasons } & \multicolumn{2}{|c|}{ ERA-Interim } & \multicolumn{2}{|c|}{ JRA-55 } & \multicolumn{2}{|c|}{ NCEP-DOE R-2 } & \multicolumn{2}{|c|}{ Ensemble } \\
\hline & Land & Ocean & Land & Ocean & Land & Ocean & Land & Ocean \\
\hline & & & & Northern & & & & \\
\hline Annual & $\begin{array}{c}-0.53 \\
(-1.81)\end{array}$ & $\begin{array}{c}-0.28 \\
(-1.61)\end{array}$ & $\begin{array}{c}-0.56 \\
(-1.89)\end{array}$ & $\begin{array}{c}-0.39 \\
(-2.35)\end{array}$ & $\begin{array}{c}-0.44 \\
(-1.43)\end{array}$ & $\begin{array}{c}-0.35 \\
(-2.04)\end{array}$ & $\begin{array}{c}-0.52 \\
(-1.78)\end{array}$ & $\begin{array}{c}-0.34 \\
(-1.99)\end{array}$ \\
\hline Winter & $\begin{array}{c}-0.31 \\
(-0.59)\end{array}$ & $\begin{array}{c}-0.36 \\
(-1.41)\end{array}$ & $\begin{array}{c}-0.34 \\
(-0.64)\end{array}$ & $\begin{array}{c}-0.48 \\
(-1.93)\end{array}$ & $\begin{array}{c}-0.14 \\
(-0.26)\end{array}$ & $\begin{array}{c}-0.43 \\
(-1.75)\end{array}$ & $\begin{array}{c}-0.30 \\
(-0.56)\end{array}$ & $\begin{array}{c}-0.42 \\
(-1.67)\end{array}$ \\
\hline Spring & $\begin{array}{c}-0.79 \\
(-2.49)\end{array}$ & $\begin{array}{c}-0.04 \\
(-0.19)\end{array}$ & $\begin{array}{c}-0.86 \\
(-2.65)\end{array}$ & $\begin{array}{c}-0.21 \\
(-1.03)\end{array}$ & $\begin{array}{c}-0.58 \\
(-1.67)\end{array}$ & $\begin{array}{c}-0.04 \\
(-0.21)\end{array}$ & $\begin{array}{c}-0.81 \\
(-2.52)\end{array}$ & $\begin{array}{c}-0.10 \\
(-0.49)\end{array}$ \\
\hline Summer & $\begin{array}{c}-0.30 \\
(-7.92)\end{array}$ & $\begin{array}{c}-0.23 \\
(-3.10)\end{array}$ & $\begin{array}{c}-0.34 \\
(-8.44)\end{array}$ & $\begin{array}{c}-0.48 \\
(-6.42)\end{array}$ & $\begin{array}{c}-0.49 \\
(-8.65)\end{array}$ & $\begin{array}{c}-0.35 \\
(-3.56)\end{array}$ & $\begin{array}{c}-0.32 \\
(-8.09)\end{array}$ & $\begin{array}{c}-0.34 \\
(-4.36)\end{array}$ \\
\hline Fall & $\begin{array}{c}-0.71 \\
(-2.49)\end{array}$ & $\begin{array}{c}-0.41 \\
(-2.81)\end{array}$ & $\begin{array}{c}-0.78 \\
(-2.68)\end{array}$ & $\begin{array}{c}-0.46 \\
(-3.30)\end{array}$ & $\begin{array}{c}-0.37 \\
(-1.29)\end{array}$ & $\begin{array}{c}-0.58 \\
(-4.04)\end{array}$ & $\begin{array}{c}-0.70 \\
(-2.44)\end{array}$ & $\begin{array}{c}-0.44 \\
(-3.10)\end{array}$ \\
\hline Annual & $\begin{array}{c}-0.01 \\
(-0.07)\end{array}$ & $\begin{array}{c}+0.53 \\
(+1.61)\end{array}$ & $\begin{array}{c}-0.02 \\
(-0.18)\end{array}$ & $\begin{array}{l}\text { Southern } \\
\quad+0.16 \\
(+0.50)\end{array}$ & $\begin{array}{c}+0.04 \\
(+0.33)\end{array}$ & $\begin{array}{c}+0.03 \\
(+0.11)\end{array}$ & $\begin{array}{c}-0.01 \\
(-0.06)\end{array}$ & $\begin{array}{c}+0.32 \\
(+1.03)\end{array}$ \\
\hline Winter & $\begin{array}{c}-0.01 \\
(-0.11)\end{array}$ & $\begin{array}{c}+0.38 \\
(+0.99)\end{array}$ & $\begin{array}{c}-0.02 \\
(-0.19)\end{array}$ & $\begin{array}{c}+0.07 \\
(+0.18)\end{array}$ & $\begin{array}{c}+0.05 \\
(+0.37)\end{array}$ & $\begin{array}{c}-0.28 \\
(-0.84)\end{array}$ & $\begin{array}{c}-0.01 \\
(-0.10)\end{array}$ & $\begin{array}{c}+0.16 \\
(+0.44)\end{array}$ \\
\hline Spring & $\begin{array}{c}-0.01 \\
(-0.10)\end{array}$ & $\begin{array}{c}+0.34 \\
(+0.91)\end{array}$ & $\begin{array}{c}-0.02 \\
(-0.14)\end{array}$ & $\begin{array}{c}+0.17 \\
(+0.48)\end{array}$ & $\begin{array}{c}+0.03 \\
(+0.22)\end{array}$ & $\begin{array}{c}-0.06 \\
(-0.19)\end{array}$ & $\begin{array}{c}-0.01 \\
(-0.08)\end{array}$ & $\begin{array}{c}+0.26 \\
(+0.72)\end{array}$ \\
\hline Summer & $\begin{array}{c}-0.01 \\
(-0.04)\end{array}$ & $\begin{array}{c}+0.70 \\
(+2.66)\end{array}$ & $\begin{array}{c}-0.01 \\
(-0.13)\end{array}$ & $\begin{array}{c}+0.31 \\
(+1.23)\end{array}$ & $\begin{array}{c}+0.01 \\
(+0.12)\end{array}$ & $\begin{array}{c}+0.57 \\
(+2.53)\end{array}$ & $\begin{array}{c}-0.00 \\
(-0.01)\end{array}$ & $\begin{array}{c}+0.55 \\
(+2.18)\end{array}$ \\
\hline Fall & $\begin{array}{c}-0.02 \\
(-0.14)\end{array}$ & $\begin{array}{c}+0.58 \\
(+1.95)\end{array}$ & $\begin{array}{c}-0.02 \\
(-0.21)\end{array}$ & $\begin{array}{c}+0.14 \\
(+0.49)\end{array}$ & $\begin{array}{c}+0.06 \\
(+0.48)\end{array}$ & $\begin{array}{c}-0.07 \\
(-0.28)\end{array}$ & $\begin{array}{c}-0.01 \\
(-0.08)\end{array}$ & $\begin{array}{c}+0.31 \\
(+1.08)\end{array}$ \\
\hline
\end{tabular}

over the HMA at $0.05_{0.01}(0.04-0.06)$ million $\mathrm{km}^{2}$ decade $^{-1}$ followed by the western United States and Andes at the rate of $0.01_{0.05}(0.00-0.02)$ million $\mathrm{km}^{2}$ decade $^{-1}$ and $0.01_{0.05}(-0.03-0.02)$ million $\mathrm{km}^{2}$ decade $^{-1}$. It is important to note that the highest percentage reduction is observed over the Alps at $3.64_{0.01}(-7.54-4.84) \%$ decade $^{-1}$ followed by the western United States and HMA with reduction of $2.81_{0.05}(1.91-3.27) \%$ decade $^{-1}$ and $1.85_{0.05}$ (1.53$2.18) \%$ decade $^{-1}$, respectively. To understand where these changes have occurred, the daily ensemble-mean wet-bulb temperature was used to compute the per-pixel annual exceedance probability of potential snowfall occurrence. To that end, we created daily binary masks over the areas where the wet-bulb temperatures are below the snowfall thresholds. Then, annual binary masks of potential snowfall occurrence are produced to delineate the areas over which the potential snowfall occurs at least $25 \%, 50 \%$, and $75 \%$ of days in a year. Then a pixel-level frequency value is obtained by summing the annual binary masks over the entire 39 years of data (Figs. 7a-f). For example, when an area shows a frequency value of 10 for the $25 \%$ exceedance probability, it means that for 10 years the area could potentially receive snowfall at least $25 \%$ of the days in a year. Thus, when the frequency values are decreasing poleward it implies that the potential snowfall areas, at different annual exceedance levels, are shrinking.
Focusing on the $\mathrm{NH}$ terrestrial changes, among those regions where at least $25 \%$ of the time the snowfall occurrence is likely, eastern and southeastern Europe, the Middle East, and some regions south of central Asia have experienced significant shrinkage. From west to east, the changes extend from lowlands in Poland to the Baltic Sea, southwestern Russia, southern Kazakhstan, and the Aral Sea. Over southeastern Europe, Serbia, Bulgaria, and Romania have been experiencing shrinkage of snowfall area. In the Middle East, the changes are detected over the central west portion of Turkey and the foothills of the Alborz and Zagros mountain ranges in the Iranian Plateau. The areas that are likely to receive snowfall more than $50 \%$ of the time are shrinking mostly over North America's Rocky Mountains, Canada's boreal forests, northwest Russia, and southwest Scandinavia, especially over Finland and Sweden. The shrinkage areas, with at least $75 \%$ of snowfall occurrence, are over the southern Himalayan range of HMA, eastern parts of the Tibetan Plateau, and northern Siberia. Over North America, much of the shrinkage is observed over the Brooks mountain range in Alaska and Canadian barren grounds.

\section{d. Changes in transition latitudes}

In this section we confine our considerations only to the $\mathrm{NH}$ for characterizing the changes on the boundary of the potential snowfall areas. As previously noted, the motivation is to understand where and to what extent 


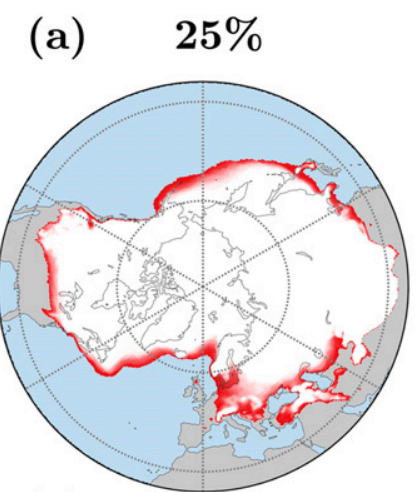

(d)

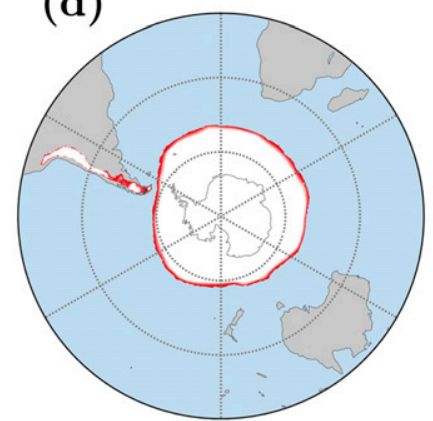

(b) $\quad 50 \%$

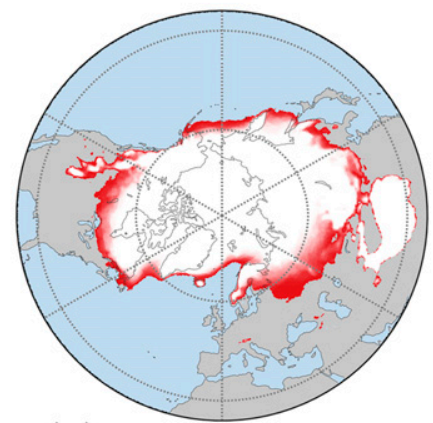

(e)

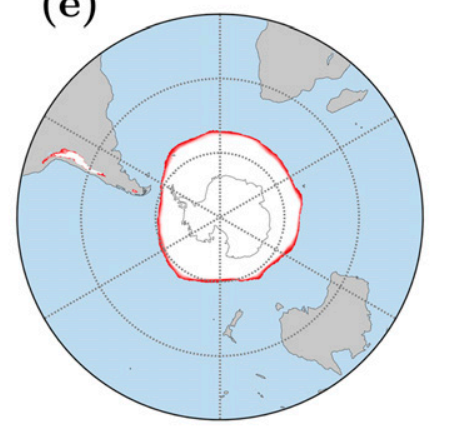

(c) $\quad 75 \%$

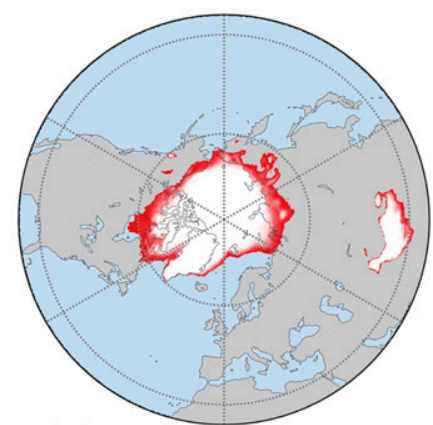

(f)

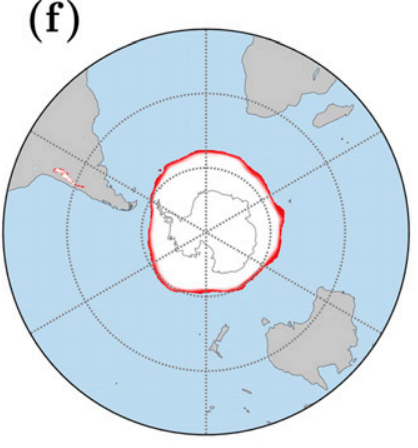

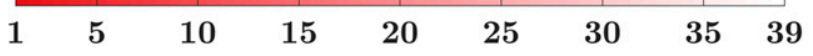

FIG. 7. Hemispheric maps showing areas over which annual frequency of potential snowfall occurrence have changed during the last four decades. Results are shown for exceedance probabilities of (left) $25 \%$, (center) $50 \%$, and (right) $75 \%$ in the (a)-(c) NH and (d)-(f) SH.

the snowfall-to-rainfall transition latitudes are moving. To that end, the boundary of the potential snowfall areas, with a decadal exceedance probability of $25 \%, 50 \%$, and $75 \%$, are quantified. For example, the latitudes with $25 \%$ exceedance probability represent the boundary of the areas within which snowfall occurrence is probable at least $25 \%$ of the days within a decade. This decadal representation is used to capture the long-term trends over a window of time and cancel out the short-term interannual variability.

The transition latitudes with exceedance probability of $50 \%$ for a moving time window of 10 years are shown in Fig. 8a. Each line depicts the position of the boundary with lighter colors representing earlier time periods. The changes are more noticeable over land than over oceans, particularly over North America and Eurasia. Figures $8 \mathrm{c}-\mathrm{e}$ and $8 \mathrm{f}-\mathrm{h}$ provide a zoomed view over the areas of significant changes.

Over North America, 25\% transition latitudes remain fairly stable with a little fluctuation in the Midwest and eastern United States (Fig. 8c); however, the northward retreat is fairly high over Europe and eastern Asia (Fig. 8f). At the 50\% level, the retreat is noticeable over the Canadian provinces of Manitoba, Ontario, and Quebec
(Fig. 8d). Isolated islands of changes are formed over the western United States and HMA (Figs. 8d,g). Because of the steepness of the mountainous areas, changes of areal extent are small and rates should be further studied as a function of elevation. Over Europe and central Asia, a significant northward retreat is observed over the Norwegian Sea, eastern Russia, and northern Kazakhstan (Fig. 8g). For the 75\% level, transition latitudes are markedly retracting over northern Quebec in Canada (Fig. 8e), northern Russia, and the western Tibetan Plateau (Fig. 8h). The annual zonal-mean values of the transition latitudes and their poleward retreat rates are computed over $15^{\circ}$ longitude intervals. Figure $8 \mathrm{~b}$ shows northward retreat rates greater than $0.7^{\circ}$ decade $^{-1}$ over Europe within $0^{\circ}-30^{\circ} \mathrm{E}$. Also, parts of central Asia from $75^{\circ}$ to $90^{\circ} \mathrm{E}$, comprising the HMA, are experiencing a significant retreat rate of $0.45^{\circ}$ decade $^{-1}$.

\section{e. Changes in total snowfall and snowfall-to-precipitation ratio}

Focusing on the NH, the spatial trends in annual total snowfall (snow water equivalent) from ERA-Interim and 
(a)

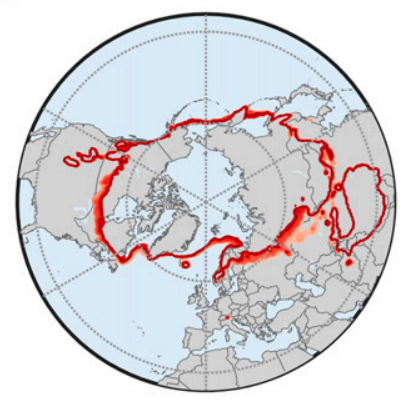

2017

2008

1998

1988 (b)

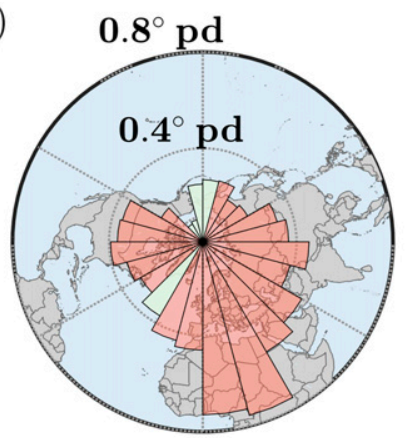

Significant $\square$ Insignificant (c) $\mathbf{2 5} \%$

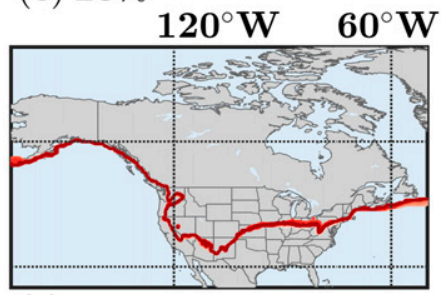

(f)

$0^{\circ}$

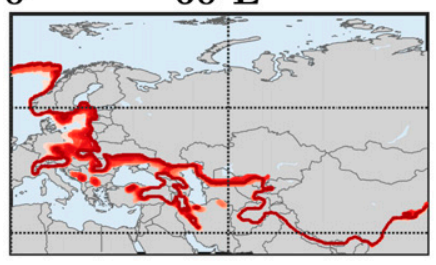

1988 (d) $\mathbf{5 0} \%$

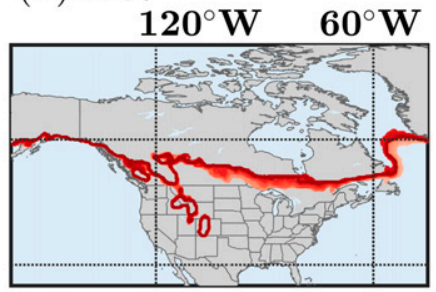

(g)

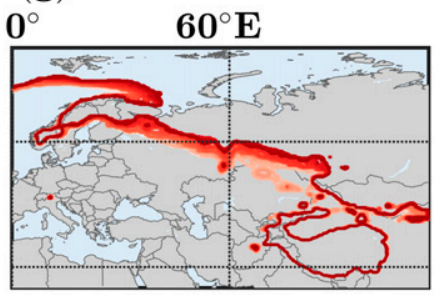

1998

2008 (e) $\mathbf{7 5} \%$

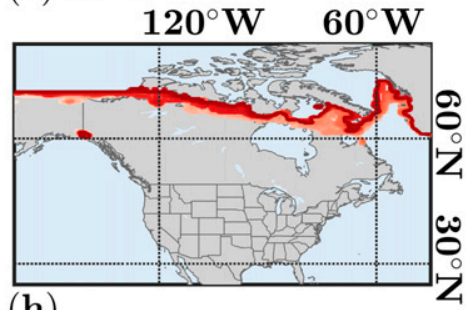

(h)
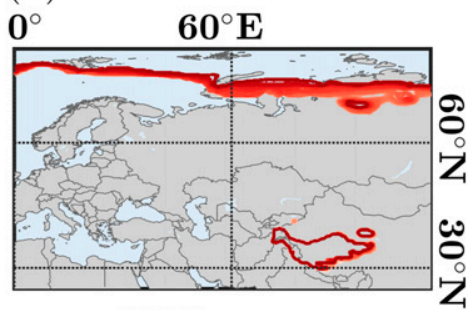

2017

FIG. 8. (a) Snowfall-to-rainfall transition latitudes as the boundary of potential snowfall areas with an exceedance probability of $50 \%$ over a sliding time window of 10 years, (b) the zonal-mean values of northward retreat $\left({ }^{\circ}\right.$ decade $^{-1}$, labeled pd in the figure), and the zoomed areas for different exceedance probabilities over (c)-(e) North America and (f)-(h) Eurasia.

the Pentad GPCP are shown in Figs. 9a and 9b, respectively. It is clear that compared to ERA-Interim, GPCP shows more coherent declining trends over the oceans. GPCP shows a significant declining trend of $30 \mathrm{~mm}_{\text {decade }}{ }^{-1}$ over the Labrador Sea, the Baffin Bay, the western coast of Greenland, and Hudson Bay in northeastern Canada. Over the Greenland Sea and the Norwegian Sea, ERA-Interim and GPCP agree that negative snowfall trends exist. Some disagreement can be observed over the northern Barents Sea where the ERAInterim suggests a positive snowfall trend of around $20 \mathrm{~mm} \mathrm{decade}^{-1}$ while GPCP shows some incoherent negative trend of around $30 \mathrm{~mm}_{\text {decade }}{ }^{-1}$.

Over the terrestrial regions, both products agree on negative total snowfall over the Midwest United States near Lake Superior and part of the western United States. Over Asia, the products agree on negative snowfall trend over the southern parts of the Tibetan Plateau but they disagree over northeastern China where ERA-Interim suggests a negative trend of around $10 \mathrm{~mm}$ decade $^{-1}$ whereas GPCP suggests a smaller and patchy positive trend of about $5 \mathrm{~mm} \mathrm{decade}{ }^{-1}$. The disagreement between products is more pronounced over Greenland where GPCP suggests a decreasing snowfall trend of around $25 \mathrm{~mm}$ decade ${ }^{-1}$ whereas ERA-Interim reports no significant changes except over a small area with a coherent positive snowfall trend of around $10 \mathrm{~mm} \mathrm{decade}^{-1}$.

Figure 9c shows the trend values of annual snowfall over NH climate classes and mountain ranges. Over the polar climate class, all GPCP-derived products agree on a negative trend in total annual snowfall at 15.72 (15.7216.31) $\mathrm{mm} \mathrm{decade}^{-1}$ whereas ERA-Interim suggests insignificant smaller trend value of $0.79 \mathrm{~mm} \mathrm{decade}^{-1}$. 


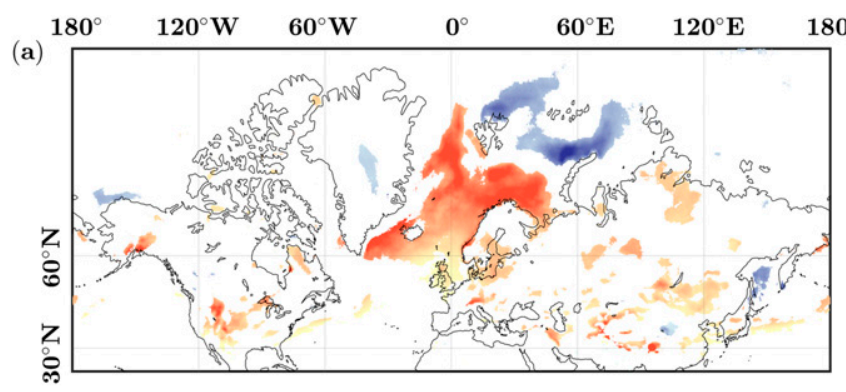

(b)

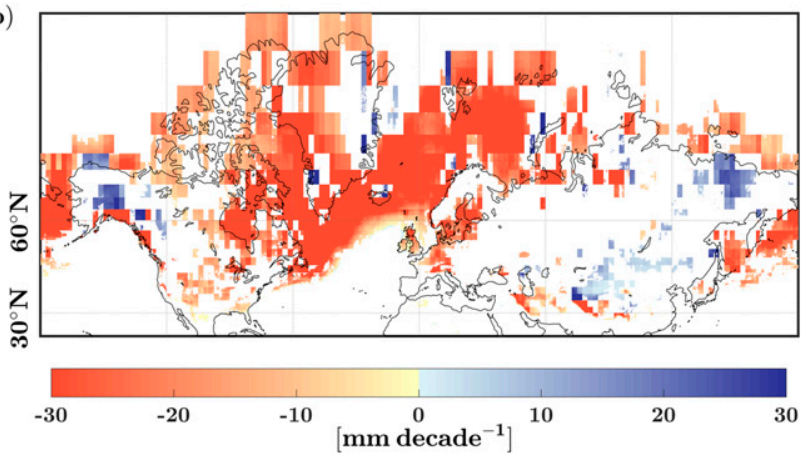

(c)

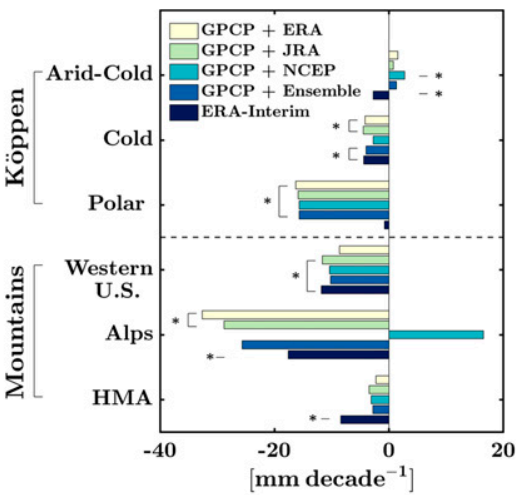

FIG. 9. Spatial distribution of trends in total annual snowfall (snow water equivalent) obtained from (a) ERAInterim and (b) GPCP data over the NH, and (c) their spatial mean values over the studied Köppen-Geiger climate classes and mountain ranges. Significant trend values $(\alpha=0.05)$ are marked by an asterisk.

Among the three climate classes, agreement exists over the cold climate where they suggest comparably negative snowfall trend of around $2.77-4.48 \mathrm{~mm} \mathrm{decade}^{-1}$. However, over the arid cold climate, all GPCP combinations suggest a positive trend in snowfall at a rate of $1.34(0.78$ 2.73) $\mathrm{mm} \mathrm{decade}^{-1}$ whereas ERA-Interim suggests a significantly negative trend of $2.77 \mathrm{~mm} \mathrm{decade}{ }^{-1}$. There is agreement about a decreasing trend in annual snowfall over the studied mountainous ranges, except over HMA. All GPCP-derived trends and ERA-Interim suggest the highest decrease of annual snowfall of more than $20 \mathrm{~mm}$ decade $^{-1}$ over the Alps, except the combination of GPCP and NCEP-DOE R-2. Over HMA, analyses based on ERA-Interim suggest a significant negative trend at the rate of $8.42 \mathrm{~mm}$ decade ${ }^{-1}$, whereas the GPCP data do not indicate any significant trend in total snowfall.

Figures 10a and 10b show the spatial distribution of annual SPR trend over the NH obtained from ERAInterim and the combination of GPCP and the ensemble mean, respectively. It is evident that in GPCP and ERA-Interim most parts of the oceans are experiencing a significant decrease in SPR; however, GPCP suggests a stronger negative trend of around $8 \%$ decade $^{-1}$ compared to ERA-Interim at $4 \%$ decade $^{-1}$. It should be noted that in higher-latitude oceans, the absence of a trend in GPCP is due to the unavailability of GPCP dataset over this region. Over the terrestrial regions, only a few regions exhibit significant trends around 4\% decade ${ }^{-1}$. Over North America, GPCP suggests that the SPR is decreasing over the Great Plains in the United States and Manitoba, Ontario, and Quebec provinces around the Hudson Bay in Canada. Disagreement between GPCP and ERA-Interim exists over the western United States, where GPCP suggest a negative trend whereas a positive trend is suggested by ERA-Interim. In Europe, for both products, a significant decreasing trend is detected over parts of Finland, Sweden, Poland, and Germany on the coastal region of the Baltic Sea as well as over the United Kingdom. Central Iran, western Turkmenistan, the central Tibetan Plateau, and the Siberian Plateau in Asia have been experiencing a decrease in SPR, while an increase in parts of the Mongolian Plateau is significant and is around $4 \%$. It should be noted that in general the quality of overland satellite precipitation is lower than over ocean (Kubota et al. 2009). This uncertainty could be one of the main reasons that the detected trends are more coherent over oceans in GPCP.

Over all the studied climate classes in the $\mathrm{NH}$, the trend in SPR by the ERA-Interim matches closely with the one computed from the GPCP data. The largest decrease occurs over the polar climate region with $1.1 \%$ decade $^{-1}$ in ERA-Interim and $1.49(1.33-1.59) \%$ decade $^{-1}$ in GPCP, followed by the cold climate region at the rate of $0.68 \%$ decade $^{-1}$ and $0.95(0.75-1.02) \%$ decade $^{-1}$, 

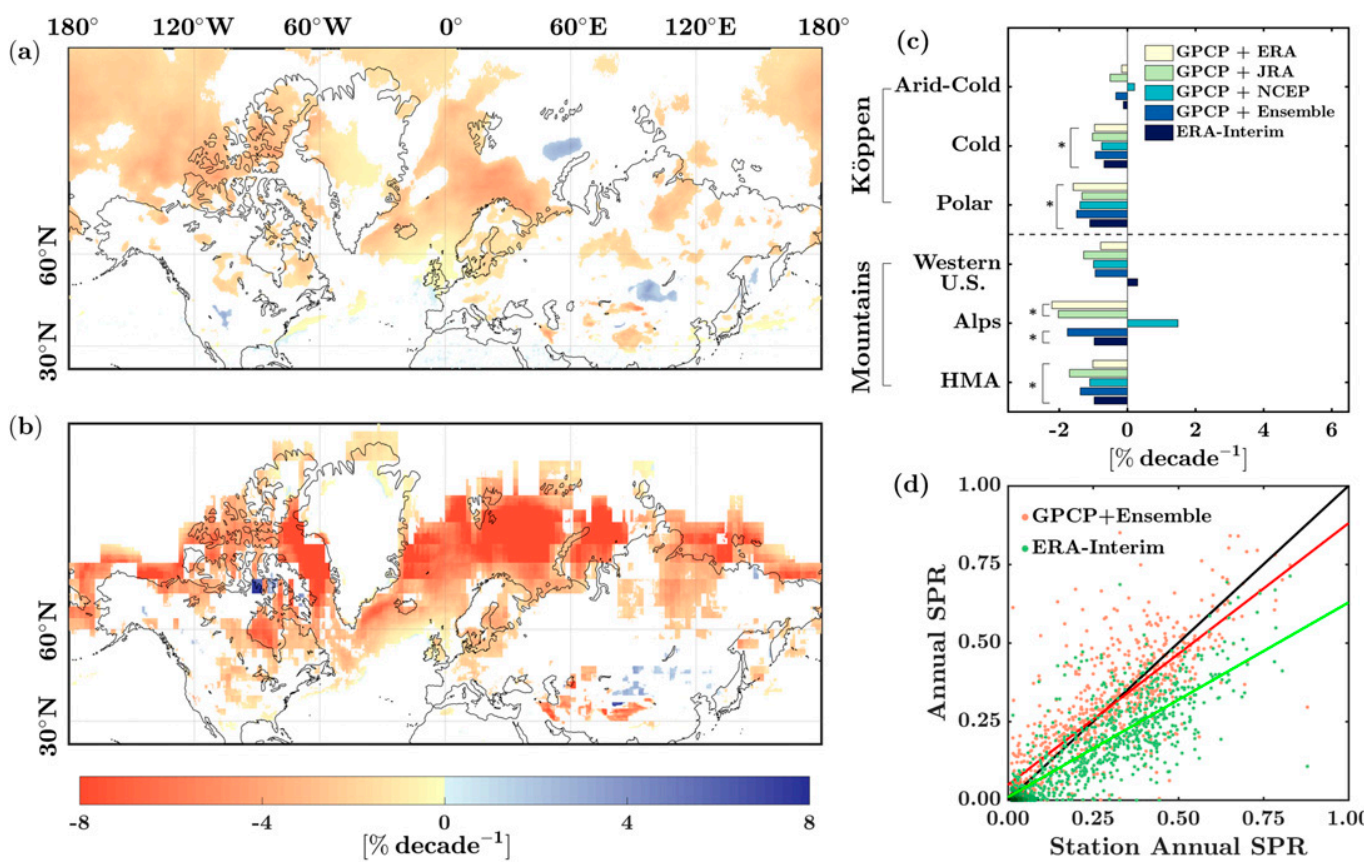

(d)

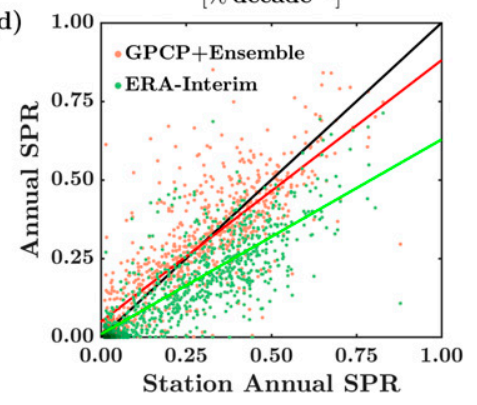

FIG. 10. Spatial distribution of trends in annual SPR over the NH, obtained from (a) ERA-Interim and (b) GPCP data and (c) their spatial mean values over the studied Köppen-Geiger climate classes and mountain ranges, as well as (d) the annual SPR values against 803 station years from the GSOD gauge station data with an SPR greater than 0.01 . Significant trend values $(\alpha=0.05)$ are marked by an asterisk in $(\mathrm{c})$.

respectively. However, no significant trend is observed over the arid cold class (Fig. 10c). Among the mountain regions, surprisingly, there is no significant trend over the western United States. There is an agreement between all datasets that the highest significant decrease of SPR ( $2 \%$ ) has occurred over the Alps, excluding the data from the NCEP-DOE R-2. All data products denote that the HMA has experienced small but significantly negative trends ranging from $0.97 \%$ to $1.7 \%$ decade $^{-1}$.

To validate the results of the SPR calculation, the annual values from GPCP and ERA-Interim are compared to 803 NCDC gauge station years between 2011 and 2015 (Fig. 10d). Quality metrics including the coefficient of determination $R^{2}$, percentage bias (PBIAS), probability of detection (POD), false alarm ratio (FAR), and critical success index (CSI) are used (see appendix C). The results suggest that GPCPderived SPR values perform better than those based on ERA-Interim with an $R^{2}$ value of 0.65 compared to 0.61 and a PBIAS of $1.06 \%$ compared to $-34.69 \%$, respectively. However, in terms of capturing the snowfall occurrences, ERA-Interim and the combination of GPCP and the ensemble mean of the wet-bulb temperature have comparable performance. Specifically, GPCPderived values and ERA-Interim have POD values of
0.91 and 1, FAR of 0.33 and 0.34 , and CSI of 0.62 and 0.66 , respectively.

\section{Conclusions and discussion}

In this study, we used three reanalysis datasets and showed that the global-mean wet-bulb temperature trend increased significantly in the past four decades, except over the SH oceans. The observed regional warming trend in wet-bulb temperature is $\sim 20 \%$ larger than the regional air temperature trends of $0.065^{\circ}$ $0.59^{\circ} \mathrm{C}$ decade $^{-1}$ over the eastern Siberian transect observed during 1956-90 (Romanovsky et al. 2007) and $0.20^{\circ} \mathrm{C}$ decade ${ }^{-1}$ over the U.S. Midwest, Canadian prairies, and western Arctic during 1948-2010 (Isaac and Van Wijngaarden 2012). This implies an increase in near-surface atmospheric moisture content since the wet-bulb temperature increases monotonically with the relative humidity.

While a coherent warming trend in wet-bulb temperature exists all over the Arctic region, only parts of Antarctica are experiencing a warming trend. The wetbulb temperature over Antarctica is mostly below the snowfall threshold and this warming trend may not directly lead to a reduction of snowfall accumulation. However, the significant wet-bulb temperature trends 
of $\sim 0.4^{\circ} \mathrm{C} \mathrm{decade}^{-1}$ are lower than the air-temperature trend of $0.56^{\circ} \mathrm{Cdecade}^{-1}$ reported over parts of the Antarctica (Turner et al. 2005). This results in an increase of wet-bulb depression over the years, which in turn increases the ablation rate at subzero temperatures (Budd 1967).

Among the three studied Köppen-Geiger climate classes and four mountainous regions, the $\mathrm{NH}$ polar class and the Alps are experiencing the highest warming trend. On average, the Alps, the western United States, High Mountain Asia (HMA), and the Andes have experienced a reduction in potential snowfall area at 0.02 million $\mathrm{km}^{2}$ decade $^{-1}$ with the Alps losing the highest proportion of potential snowfall areas at $3.64 \%$ decade $^{-1}$. Tracking the transition latitudes that delineate the changes from snowfall-to-rainfall regimes showed an annual retreat toward the North Pole in the $\mathrm{NH}$ at $0.7^{\circ}$ and $0.45^{\circ}$ decade $^{-1}$ over Europe and central Asia.

Data from ERA-Interim and the Global Precipitation Climatology Project (GPCP) agree on a significant decrease of total snowfall amount over the northern Atlantic Ocean, Greenland Sea, Norwegian Sea, and Barents Sea with a rate of $10-30 \mathrm{~mm}_{\text {decade }}{ }^{-1}$. Terrestrial regions of total snowfall declines with a rate greater than $10 \mathrm{~mm} \mathrm{decade}^{-1}$ are over the Bitterroot Range, the northern Rocky Mountains, the Great Plains, the U.S. Northwest, and northern Quebec in North America; the United Kingdom, south of Finland, north of Germany, north of Poland, and Lithuania in Europe; and the Zagros Mountains in the Iranian Plateau and southern Himalayas in Asia.

Data from ERA-Interim and the Global Precipitation Climatology Project (GPCP) agree on significant positive trends in annual snowfall amount of about $5 \mathrm{~mm}$ decade $^{-1}$ over parts of the Tibetan Plateau, which is consistent with the findings by Deng et al. (2017). The areas of agreement on SPR are over the Beaufort Sea, the Northwest Passage, the northern Atlantic Ocean, the Greenland Sea, the Norwegian Sea, and the Barents Sea. However, the rates in GPCP data are greater than $4 \%$ while in ERA-Interim the rates are largely around $2 \%$. Furthermore, negative trends in SPR were observed over the Great Plains and east of the Hudson Bay lowlands in North America; in Finland, Lithuania, Latvia, and Estonia in Europe; and in the Tibetan highlands in Asia, which are consistent with the regional studies over the United States (Feng and Hu 2007; Kunkel et al. 2009), Canada (Vincent et al. 2015), Finland (Irannezhad et al. 2017), and the Tibetan Plateau (Wang et al. 2016).

The rate of changes in SPR in GPCP seems to be systematically higher than ERA-Interim, especially over oceans. Due to spatial changes in total precipitation, there have been some differences between the global patterns of change in total snowfall and SPR. Over Greenland, GPCP shows a decline in total snowfall but no changes in SPR while ERA-Interim shows an appreciable increase of total snowfall and a decrease of SPR. Thus, from the GPCP data the total precipitation should remain constant while ERA-Interim denotes that the total precipitation has increased.

Over the Alps, not only the total snowfall but also the solid fraction of precipitation is decreasing significantly. Thus, either the total precipitation has increased or the reduction of snowfall amount has been faster than the reduction in total precipitation. Over the western United States, the total snowfall is decreasing significantly but not the SPR. In other words, the decline of precipitation and snowfall has been proportional. The results over HMA are ambiguous. GPCP data do not indicate any significant changes in total snowfall while ERA-Interim denotes a significant decline. However, both datasets agree that the SPR has declined.

Certainly, the linkage between the changes of snowfall and snow cover is a future line of research. Brown and Robinson (2011) report decreases in NH snowcover extent of 0.8 million $\mathrm{km}^{2}$ decade $^{-1}(7 \%-11 \%)$ in March and April over the 1970-2010 period, which is consistent with the characterized changes of potential snowfall areas in section 4c. Historical information on snow-cover extent and satellite snow water equivalent data (Smith and Bookhagen 2016, 2018) are needed to investigate the competing effects of temperature and precipitation trends on global changes of snow-cover extent and snow water equivalent.

The resolution of the used reanalysis products is low and the reanalysis and satellite precipitation estimates suffer from a high degree of uncertainty. More specifically, the results reported over the mountains should be interpreted with caution and should be updated when new higher-resolution reanalysis data with more sophisticated parameterization of the effects of topographic features on precipitation become available. In addition, reanalysis products are highly inhomogeneous since the quality, quantity, and character of assimilated data change over time. For example, one of the main reasons for the observed discrepancies between the reanalysis data over the $\mathrm{SH}$ is the lack of adequately dense gauge observations. This inhomogeneity can introduce artificial trends that can affect our analyses (Long et al. 2017). Using different reanalysis products might not completely eliminate those trend due to the assimilation of similar datasets. Future studies could investigate snowfall changes in more homogeneous reanalyses datasets such as the ECMWF's 20th-century reanalysis (Poli et al. 2016) or NOAA-CIRES's 20th-Century Reanalysis (Compo et al. 2011). 
A similar problem exists for the analyzed Pentad GPCP products because of coarse spatial resolution and the fact that satellite precipitation still suffers from a large degree of uncertainty in retrievals of orographic precipitation over complex terrain. Future studies can also focus on the usage of other ancillary data such as vertical temperature lapse rate for characterizing precipitation phase to improve the inference over mountain ranges. Moreover, finding ways to refine our inference using snowfall data from recent spaceborne active radars on board the GPM and CloudSat satellites could be another future line of research.

And last, it is important to note that the uncertainty of our analysis and the derived conclusions are subject to the accuracy of the data used and techniques explained such as the lower skill of precipitation phase-partitioning methods at near-freezing temperature (Ding et al. 2014; Jennings et al. 2018). In particular, we did not make any correction for the effects of topography on both temperature and precipitation data and only extracted the information content of the available observational datasets. Developing globally accepted relationships for such corrections over important mountainous regions of the world would help to advance climate change assessments in regions with complex topography.

Acknowledgments. The first and second authors acknowledge support from the National Aeronautics and Space Administration (NASA) Precipitation Measurement Project (NNX16AO56G), New (Early Career) Investigator Program award (NIP; 80NSSC18K0742), and the grant from the Terrestrial Hydrology Program (THP; 80NSSC18K152). The first author also acknowledges the support provided by Sommerfield Graduate Fellowship at University of Minnesota-Twin Cities during his first year of study. NCAR is sponsored by the National Science Foundation.

\section{APPENDIX A}

\section{Computation of the Wet-Bulb Temperature}

Here, the wet-bulb temperature is calculated from Eq. (A1) (Stull 2016) using an iterative Newton-Raphson method:

$T_{w}=T_{a}-\frac{L_{v}}{C_{p}} \mathscr{E} A\left[\frac{1}{P \exp \left(\frac{B}{T_{w}}\right)-A}-\frac{\mathrm{RH}}{P \exp \left(\frac{B}{T_{a}}\right)-A}\right]$, where $T_{w}$ is the 2 -m wet-bulb temperature $(\mathrm{K}), T_{a}$ denotes 2-m air temperature $(\mathrm{K}), L_{v}$ is the latent heat of vaporization $\left(\mathrm{J} \mathrm{kg}^{-1}\right), C_{p}$ refers to the specific heat constant for dry air $\left(\mathrm{kJ} \mathrm{kg}^{-1} \mathrm{~K}^{-1}\right), \varepsilon$ is the ratio of dry gas constant to water vapor gas constant, $P$ denotes station pressure (hPa), $\mathrm{RH}$ is the relative humidity, and $A=$ $2.53 \times 10^{9} \mathrm{hPa}$ and $B=5420 \mathrm{~K}$ are empirical constants.

Due to the lack of information on RH within ERAInterim, it was computed from dewpoint temperature and air temperature using Eq. (A2) provided by ECMWF (2015):

$$
\mathrm{RH}=\exp \left[17.502\left(\frac{T_{d}-273.16}{T_{d}-32.19}-\frac{T_{a}-273.16}{T_{a}-32.19}\right)\right],
$$

where $T_{d}$ is the dewpoint temperature $(\mathrm{K})$.

\section{APPENDIX B}

\section{Details of Statistical Trend Analysis}

For brevity, here we explain the Theil-Sen method for trend analysis adopting the notation only for the wetbulb temperature. To that end, let us assume that $\mathbf{T}_{\mathrm{wb}}=\left\{\bar{T}_{\mathrm{wb}}^{1}, \bar{T}_{\mathrm{wb}}^{2}, \ldots, \bar{T}_{\mathrm{wb}}^{n}\right\}$ represents annual time series of hemispheric-mean wet-bulb temperatures for year $\mathbf{y}=\left\{y^{1}, y^{2}, \ldots, y^{n}\right\}$. The Theil-Sen estimate of the linear slope $\beta$ is defined as

$$
\begin{aligned}
& \beta=\operatorname{median}\left(\frac{\bar{T}_{\mathrm{wb}}^{j}-\bar{T}_{\mathrm{wb}}^{i}}{y^{j}-y^{i}}\right), \quad i=1,2, \ldots, n-1, \\
& j=2,3, \ldots, n, \quad j>i .
\end{aligned}
$$

Numerous tests have been examined to quantify the statistical significance of the Theil-Sen estimator, here we adopt the bootstrap Mann-Kendall (MK) test. In summary, the MK test computes the following test statistic:

$$
S=\sum_{k=1}^{n-1} \sum_{j=k+1}^{n} \operatorname{sgn}\left(\bar{T}_{\mathrm{wb}}^{j}-\bar{T}_{\mathrm{wb}}^{k}\right),
$$

where $j>k$ and $\operatorname{sgn}(\cdot)$ refers to the signum function. Positive (negative) values of $S$ imply a positive (negative) trend in the time series. Under the null hypothesis, Kendall (1948) showed that the test statistic $S$ is asymptotically a zero-mean normally distributed random variable with variance $\operatorname{Var}(S)=\left[n(n-1)(2 n+5)-\sum_{i=1}^{q} t_{i}\left(t_{i}-1\right)\left(2 t_{i}+5\right)\right] / 18$, where, $q$ is the total number of groups of same observations or ties and $t_{i}$ is the number of observation in the $i$ th tied group. Thus, the standard test statistic $Z$ is defined as follows: 
TABLE C1. Statistical measures for performance evaluation of the derived wet-bulb temperature and SPR.

\begin{tabular}{lcc}
\hline \hline Index & Formula & Range \\
\hline Coefficient of determination $\left(R^{2}\right)$ & $\left\{\frac{1}{N_{s}-1} \sum_{i=1}^{N_{s}}\left[\frac{\left.\left.\hat{x}_{\mathrm{ML}}(i)-\mu_{\mathrm{ML}}\right]\left[\frac{x_{G}(i)-\mu_{G}}{\sigma_{\mathrm{ML}}}\right]\right\}^{2}}{\sigma^{2}}\right.\right.$ & $-\infty$ to 1 \\
Percent bias (PBIAS) & $\frac{\sum_{i=1}^{N_{s}}\left[\hat{x}_{\mathrm{ML}}(i)-x_{G}(i)\right]}{\sum_{i=1}^{N_{s}} x_{G}(i)} \times 100$ \\
Probability of detection (POD) & $\frac{n_{H}}{n_{H}+n_{M}}$ \\
False alarm ratio (FAR) & $\frac{n_{F}}{n_{H}+n_{F}}$ \\
Critical success index (CSI) & $\frac{n_{H}}{n_{H}+n_{M}+n_{F}}$ \\
\hline
\end{tabular}

$$
Z=\left\{\begin{array}{ccc}
\frac{S-1}{\sqrt{\operatorname{Var}(S)}} & \text { if } & S>0 \\
0 & \text { if } & S=0 \\
\frac{S+1}{\sqrt{\operatorname{Var}(S)}} & \text { if } & S<0
\end{array}\right.
$$

where the null hypothesis can be rejected if $|Z| \geq Z_{1-\alpha / 2}$, at level of significance $\alpha$.

The asymptotic null distribution of the MK test statistic $S \tilde{\sim} \mathscr{N}[0, \operatorname{Var}(S)]$ is valid under the assumption of serial independence (von Storch 1995). To formally account for the effects of serial dependence, we confine our consideration to the classic moving-block bootstrap (MBB; Liu and Singh 1992).

Specifically, let us assume that $S$ is the MK test statistic of the original annual time series $\mathbf{T}_{\mathrm{wb}}=\left\{\bar{T}_{\mathrm{wb}}^{1}, \bar{T}_{\mathrm{wb}}^{2}, \ldots, \bar{T}_{\mathrm{wb}}^{n}\right\}$. Given the time series, a serial correlation length $r$ at significance level $\alpha$ is computed and the length of the block is set to $l=r+1$. The time series $\mathbf{T}_{\mathrm{wb}}$ is then divided into $N=n-l+1$ overlapping blocks $\xi_{i}:=\left\{\bar{T}_{\mathrm{wb}}^{i}, \ldots, \bar{T}_{\mathrm{wb}}^{i+l-1}\right\}$, with probability of occurrence equal to $1 / N$, where $i=1, \ldots, N$ and $l / n \rightarrow 0$ as $n, l \rightarrow \infty$. A number of $k=n / l$ blocks $\left\{\xi_{1}^{* b}, \xi_{2}^{* b}, \ldots, \xi_{k}^{* b}\right\}$ are sampled with replacement from $\xi_{1}, \xi_{2}, \ldots, \xi_{N}$ and concatenated to reconstruct $B$ bootstrap pseudo time series as $\bar{T}_{\mathrm{wb}}^{* b}=\left\{\xi_{1}^{* b}, \xi_{2}^{* b}, \ldots, \xi_{k}^{* b}\right\}$, where $b=1,2, \ldots, B$. Bootstrap empirical distribution of MK test statistic $S^{*}$ is obtained from the pseudo bootstrap time series $\bar{T}_{\mathrm{wb}}^{* b}$ and the significance of trend is finally computed by applying a two-tailed hypothesis test.
If the MK test statistic $S$ of the original time series is higher than the 97.5 th percentile or lower than 2.5 th percentile of the empirical distribution of test statistic $S^{*}$, the hypothesis, that there is no trend in the data, is rejected. Throughout, for computation of the empirical distribution of MK test statistic, we set $B=3000$.

\section{APPENDIX C}

\section{Quality Metrics}

Table $\mathrm{C} 1$ shows the used quality metrics in this study: $\hat{x}_{\mathrm{ML}}(i)$ is the maximum likelihood estimate for $i$ th station day (or year) with standard deviation $\sigma_{\mathrm{ML}}, x_{G}(i)$ is the corresponding gauge observation with standard deviation $\sigma_{G}, N_{s}$ is the total number of station days (or years), and $\mu_{\mathrm{ML}}$ and $\mu_{G}$ are the mean of ML estimates and gauge observations, respectively. In computation of the false alarm ratio and critical success index, $n_{H}$ is the number of hits, $n_{M}$ is the number of misses, and $n_{F}$ is the number of false alarms. The probability of detection (POD) value refers to the proportion of correctly identified number of snowfall occurrences, the false alarm rate (FAR) refers to the proportion of incorrectly identified number of snowfall occurrences, and the critical success index (CSI) penalizes both misses and false alarms.

\section{REFERENCES}

Adler, R. F., and Coauthors, 2003: The version-2 Global Precipitation Climatology Project (GPCP) monthly precipitation analysis 
(1979-present). J. Hydrometeor., 4, 1147-1167, https://doi.org/ 10.1175/1525-7541(2003)004<1147:TVGPCP $>2.0 . C O ; 2$.

Ashfaq, M., S. Ghosh, S. C. Kao, L. C. Bowling, P. Mote, D. Touma, S. A. Rauscher, and N. S. Diffenbaugh, 2013: Nearterm acceleration of hydroclimatic change in the western U.S. J. Geophys. Res. Atmos., 118, $10676-10$ 693, https://doi.org/ 10.1002/jgrd.50816.

Barnett, T. P., J. C. Adam, and D. P. Lettenmaier, 2005: Potential impacts of a warming climate on water availability in snowdominated regions. Nature, 438, 303-309, https://doi.org/ 10.1038/nature04141.

Behrangi, A., and Coauthors, 2016: Status of high-latitude precipitation estimates from observations and reanalyses. J. Geophys. Res. At mos., 121, 4468-4486, https://doi.org/10.1002/2015JD024546.

Blyth, S., B. Groombridge, I. Lysenko, L. Miles, and A. Newton, 2002: Mountain watch: Environmental change and sustainable development in mountains. UNEP World Conservation Monitoring Centre, $80 \mathrm{pp}$.

Bolvin, D. T., R. F. Adler, G. J. Huffman, E. J. Nelkin, and J. P. Poutiainen, 2009: Comparison of GPCP monthly and daily precipitation estimates with high-latitude gauge observations. J. Appl. Meteor. Climatol., 48, 1843-1857, https://doi.org/ 10.1175/2009JAMC2147.1.

Brown, R. D., and D. A. Robinson, 2011: Northern Hemisphere spring snow cover variability and change over 1922-2010 including an assessment of uncertainty. Cryosphere, 5, 219-229, https://doi.org/10.5194/tc-5-219-2011.

Budd, W., 1967: Ablation from an Antarctic ice surface. Physics of Snow and Ice: International Conference on Low Temperature Science, Vol. 1, Part 1, Sapporo, Japan, Institute of Low Temperature Science, Hokkaido University, 431-446.

Carlstein, E., 1986: The use of subseries values for estimating the variance of a general statistic from a stationary sequence. Ann. Stat., 14, 1171-1179, https://doi.org/10.1214/ aos/1176350057.

Compo, G. P., and Coauthors, 2011: The Twentieth Century Reanalysis Project. Quart. J. Roy. Meteor. Soc., 137, 1-28, https:// doi.org/10.1002/qj.776.

Dai, A., 2008: Temperature and pressure dependence of the rainsnow phase transition over land and ocean. Geophys. Res. Lett., 35, L12802, https://doi.org/10.1029/2008GL033295.

Dee, D. P., and Coauthors, 2011: The ERA-Interim reanalysis: Configuration and performance of the data assimilation system. Quart. J. Roy. Meteor. Soc., 137, 553-597, https://doi.org/10.1002/qj.828.

Deng, H., N. C. Pepin, and Y. Chen, 2017: Changes of snowfall under warming in the Tibetan Plateau. J. Geophys. Res., 122, 7323-7341, https://doi.org/10.1002/2017JD026524.

Ding, B., K. Yang, J. Qin, L. Wang, Y. Chen, and X. He, 2014: The dependence of precipitation types on surface elevation and meteorological conditions and its parameterization. J. Hydrol., 513, 154-163, https://doi.org/10.1016/j.jhydrol.2014.03.038.

Douglas, E., R. Vogel, and C. Kroll, 2000: Trends in floods and low flows in the United States: Impact of spatial correlation. J. Hydrol., 240, 90-105, https://doi.org/10.1016/S0022-1694(00)00336-X.

Ebtehaj, A., R. Bras, and E. Foufoula-Georgiou, 2016: Evaluation of ShARP passive rainfall retrievals over snow-covered land surfaces and coastal zones. J. Hydrometeor., 17, 1013-1029, https://doi.org/10.1175/JHM-D-15-0164.1.

ECMWF, 2015: IFS Documentation-cy41r1, operational implementation, part IV: Physical processes. European Centre for Medium-Range Weather Forecasts, Tech. rep., 210 pp., https://www.ecmwf.int/sites/default/files/elibrary/2015/9211part-iv-physical-processes.pdf.
Efron, B., 1979: Bootstrap methods: Another look at the jackknife. Ann. Stat., 7, 1-26, https://doi.org/10.1214/aos/1176344552.

Feng, S., and Q. Hu, 2007: Changes in winter snowfall/precipitation ratio in the contiguous United States. J. Geophys. Res., 112, D15109, https://doi.org/10.1029/2007JD008397.

Guo, L., and L. Li, 2015: Variation of the proportion of precipitation occurring as snow in the Tian Shan Mountains, China. Int. J. Climatol., 35, 1379-1393, https://doi.org/10.1002/joc.4063.

Gusain, H., V. Mishra, and M. Bhutiyani, 2014: Winter temperature and snowfall trends in the cryospheric region of northwest Himalaya. Mausam, 65, 425-432.

Hagedorn, R., F. J. Doblas-Reyes, and T. Palmer, 2005: The rationale behind the success of multi-model ensembles in seasonal forecasting-I. Basic concept. Tellus, 57A, 219-233, https://doi.org/10.3402/tellusa.v57i3.14657.

Harder, P., and J. Pomeroy, 2013: Estimating precipitation phase using a psychrometric energy balance method. Hydrol. Processes, 27, 1901-1914, https://doi.org/10.1002/hyp.9799.

Harpold, A. A., M. L. Kaplan, P. Z. Klos, T. Link, J. P. McNamara, S. Rajagopal, R. Schumer, and C. M. Steele, 2017: Rain or snow: Hydrologic processes, observations, prediction, and research needs. Hydrol. Earth Syst. Sci., 21, 1-22, https:// doi.org/10.5194/hess-21-1-2017.

Hori, M., K. Sugiura, K. Kobayashi, T. Aoki, T. Tanikawa, K. Kuchiki, M. Niwano, and H. Enomoto, 2017: A 38-year (1978-2015) Northern Hemisphere daily snow cover extent product derived using consistent objective criteria from satellite-borne optical sensors. Remote Sens. Environ., 191, 402-418, https://doi.org/10.1016/j.rse.2017.01.023.

Hou, A. Y., and Coauthors, 2014: The Global Precipitation Measurement Mission. Bull. Amer. Meteor. Soc., 95, 701-722, https://doi.org/10.1175/BAMS-D-13-00164.1.

Howat, I. M., and S. Tulaczyk, 2005: Trends in spring snowpack over a half-century of climate warming in California, USA. Ann. Glaciol., 40, 151-156, https://doi.org/10.3189/172756405781813816.

Huffman, G. J., and D. T. Bolvin, 2013: TRMM and other data precipitation data set documentation. NASA, 44 pp., http:// pmm.nasa.gov/sites/default/files/document_files/3B42_3B43_ doc_V7.pdf.

, R. F. Adler, D. T. Bolvin, and G. Gu, 2009: Improving the global precipitation record: GPCP version 2.1. Geophys. Res. Lett., 36, L17808, https://doi.org/10.1029/2009GL040000.

Irannezhad, M., A.-K. Ronkanen, S. Kiani, D. Chen, and B. Kløve, 2017: Long-term variability and trends in annual snowfall/total precipitation ratio in Finland and the role of atmospheric circulation patterns. Cold Reg. Sci. Technol., 143, 23-31, https://doi.org/10.1016/j.coldregions.2017.08.008.

Isaac, V., and W. van Wijngaarden, 2012: Surface water vapor pressure and temperature trends in North America during 1948-2010. J. Climate, 25, 3599-3609, https://doi.org/10.1175/ JCLI-D-11-00003.1.

Jennings, K. S., T. S. Winchell, B. Livneh, and N. P. Molotch, 2018: Spatial variation of the rain-snow temperature threshold across the Northern Hemisphere. Nat. Commun., 9, 1148, https://doi.org/10.1038/s41467-018-03629-7.

Kalnay, E., and Coauthors, 1996: The NCEP/NCAR 40-Year Reanalysis Project. Bull. Amer. Meteor. Soc., 77, 437-472, https:// doi.org/10.1175/1520-0477(1996)077<0437:TNYRP>2.0.CO;2.

Kanamitsu, M., W. Ebisuzaki, J. Woollen, S. K. Yang, J. J. Hnilo, M. Fiorino, and G. L. Potter, 2002: NCEP-DOE AMIP-II reanalysis (R-2). Bull. Amer. Meteor. Soc., 83, 1631-1643, https://doi.org/10.1175/BAMS-83-11-1631.

Kendall, M. G., 1948: Rank Correlation Methods. Griffin, 160 pp. 
Khaliq, M. N., T. B. Ouarda, P. Gachon, L. Sushama, and A. StHilaire, 2009: Identification of hydrological trends in the presence of serial and cross correlations: A review of selected methods and their application to annual flow regimes of $\mathrm{Ca}-$ nadian rivers. J. Hydrol., 368, 117-130, https://doi.org/10.1016/ j.jhydrol.2009.01.035.

Kienzle, S. W., 2008: A new temperature based method to separate rain and snow. Hydrol. Processes, 22, 5067-5085, https:// doi.org/10.1002/hyp.7131.

Knowles, N., M. D. Dettinger, and D. R. Cayan, 2006: Trends in snowfall versus rainfall in the western United States. J. Climate, 19, 4545-4559, https://doi.org/10.1175/JCLI3850.1.

Kobayashi, S., and Coauthors, 2015: The JRA-55 Reanalysis: General specifications and basic characteristics. J. Meteor. Soc. Japan, 93, 5-48, https://doi.org/10.2151/JMSJ.2015-001.

Kubota, T., T. Ushio, S. Shige, S. Kida, M. Kachi, and K. Okamoto, 2009: Verification of high-resolution satellite-based rainfall estimates around Japan using a gauge-calibrated ground-radar dataset. J. Meteor. Soc. Japan, 87, 203-222, https://doi.org/ 10.2151/JMSJ.87A.203

Kundzewicz, Z., and A. Robson, 2000: Detecting trend and other changes in hydrological data. WMO/TD-No. 1013, 158 pp.

Kunkel, K. E., M. Palecki, L. Ensor, K. G. Hubbard, D. Robinson, K. Redmond, and D. Easterling, 2009: Trends in twentieth-century US snowfall using a quality-controlled dataset. J. Atmos. Oceanic Technol., 26, 33-44, https://doi.org/10.1175/2008JTECHA1138.1.

Kunsch, H. R., 1989: The jackknife and the bootstrap for general stationary observations. Ann. Stat., xx, 1217-1241, https:// doi.org/10.1214/aos/1176347265.

Liu, R. Y., and K. Singh, 1992: Moving blocks jackknife and bootstrap capture weak dependence. Exploring the Limits of Bootstrap, R. Lepage and L. Billard, Eds., Wiley, 225-248.

Long, C., M. Fujiwara, S. M. Davis, D. M. Mitchell, and C. J. Wright, 2017: Climatology and interannual variability of dynamic variables in multiple reanalyses evaluated by the SPARC Reanalysis Intercomparison Project (S-RIP). Atmos. Chem. Phys., 17, 14 593-14 629, https://doi.org/10.5194/acp-17-14593-2017.

Lott, N., 1998: Global surface summary of day. National Climatic Data Center, accessed 23 July 2018, https://data.nodc.noaa.gov/ cgi-bin/iso?id=gov.noaa.ncdc:C0051.

Mankin, J. S., D. Viviroli, D. Singh, A. Y. Hoekstra, and N. S. Diffenbaugh, 2015: The potential for snow to supply human water demand in the present and future. Environ. Res. Lett., 10, 114016, https://doi.org/10.1088/1748-9326/10/11/114016.

Mann, H. B., 1945: Nonparametric tests against trend. Econometrica, 13, 245-259, https://doi.org/10.2307/1907187.

Marks, D., A. Winstral, M. Reba, J. Pomeroy, and M. Kumar, 2013: An evaluation of methods for determining during-storm precipitation phase and the rain/snow transition elevation at the surface in a mountain basin. Adv. Water Resour., 55, 98-110, https://doi.org/10.1016/j.advwatres.2012.11.012.

Marty, C., A.-M. Tilg, and T. Jonas, 2017: Recent evidence of largescale receding snow water equivalents in the European Alps. J. Hydrometeor., 18, 1021-1031, https://doi.org/10.1175/JHMD-16-0188.1.

Matoušek, J., D. M. Mount, and N. S. Netanyahu, 1998: Efficient randomized algorithms for the repeated median line estimator. Algorithmica, 20, 136-150, https://doi.org/10.1007/ PL00009190.

Mir, R. A., S. K. Jain, A. K. Saraf, and A. Goswami, 2015: Decline in snowfall in response to temperature in Satluj basin, western Himalaya. J. Earth Syst. Sci., 124, 365-382, https://doi.org/ 10.1007/s12040-015-0539-z.
Mote, P. W., S. Li, D. P. Lettenmaier, M. Xiao, and R. Engel, 2018: Dramatic declines in snowpack in the western US. npj Climate Atmos. Sci., 1, 2, https://doi.org/10.1038/s41612-018-0012-1.

Önöz, B., and M. Bayazit, 2012: Block bootstrap for Mann-Kendall trend test of serially dependent data. Hydrol. Processes, 26, 3552-3560, https://doi.org/10.1002/hyp.8438.

Peel, M. C., B. L. Finlayson, and T. A. McMahon, 2007: Updated world map of the Köppen-Geiger climate classification. Hydrol. Earth Syst. Sci., 11, 1633-1644, https://doi.org/10.5194/ hessd-4-439-2007.

Poli, P., and Coauthors, 2016: ERA-20C: An atmospheric reanalysis of the twentieth century. J. Climate, 29, 4083-4097, https://doi.org/10.1175/JCLI-D-15-0556.1.

Politis, D. N., and J. P. Romano, 1994: The stationary bootstrap. J. Amer. Stat. Assoc., 89, 1303-1313, https://doi.org/10.1080/ 01621459.1994.10476870.

Prein, A. F., and A. Gobiet, 2017: Impacts of uncertainties in European gridded precipitation observations on regional climate analysis. Int. J. Climatol., 37, 305-327, https://doi.org/10.1002/joc.4706.

Rauscher, S. A., J. S. Pal, N. S. Diffenbaugh, and M. M. Benedetti, 2008: Future changes in snowmelt-driven runoff timing over the western US. Geophys. Res. Lett., L16703, https://doi.org/ 10.1029/2008GL034424.

Romanovsky, V., T. Sazonova, V. Balobaev, N. Shender, and D. Sergueev, 2007: Past and recent changes in air and permafrost temperatures in eastern Siberia. Global Planet. Change, 56, 399413, https://doi.org/10.1016/j.gloplacha.2006.07.022.

Screen, J. A., and I. Simmonds, 2012: Declining summer snowfall in the Arctic: Causes, impacts and feedbacks. Climate Dyn., 38, 2243-2256, https://doi.org/10.1007/s00382-011-1105-2.

Sen, P. K., 1968: Estimates of the regression coefficient based on Kendall's tau. J. Amer. Stat. Assoc., 63, 1379-1389, https:// doi.org/10.1080/01621459.1968.10480934.

Sims, E. M., and G. Liu, 2015: A parameterization of the probability of snow-rain transition. J. Hydrometeor., 16, 1466-1477, https://doi.org/10.1175/JHM-D-14-0211.1.

Skofronick-Jackson, G., and Coauthors, 2017: The Global Precipitation Measurement (GPM) mission for science and society. Bull. Amer. Meteor. Soc., 98, 1679-1695, https://doi.org/ 10.1175/BAMS-D-15-00306.1.

Smith, A., N. Lott, and R. Vose, 2011: The integrated surface database: Recent developments and partnerships. Bull. Amer. Meteor. Soc., 92, 704-708, https://doi.org/10.1175/ 2011BAMS3015.1.

Smith, T., and B. Bookhagen, 2016: Assessing uncertainty and sensor biases in passive microwave data across High Mountain Asia. Remote Sens. Environ., 181, 174-185, https://doi.org/ 10.1016/J.RSE.2016.03.037.

— and - 2018: Changes in seasonal snow water equivalent distribution in High Mountain Asia (1987 to 2009). Sci. Adv., 4, e1701550, https://doi.org/10.1126/SCIADV.1701550.

Solman, S. A., and I. Orlanski, 2016: Climate change over the extratropical Southern Hemisphere: The tale from an ensemble of reanalysis datasets. J. Climate, 29, 1673-1687, https:// doi.org/10.1175/JCLI-D-15-0588.1.

Student, 1908: Probable error of a correlation coefficient. Biometrika, 6, 302-310, https://doi.org/10.1093/BIOMET/6.2-3.302.

Stull, R., 2016: Practical Meteorology: An Algebra Based Survey of Atmospheric Science. University of British Columbia, 942 pp.

Sun, Q., C. Miao, Q. Duan, H. Ashouri, S. Sorooshian, and K.-L. Hsu, 2018: A review of global precipitation data sets: Data sources, estimation, and intercomparisons. Rev. Geophys., 56, 79-107, https://doi.org/10.1002/2017RG000574. 
Theil, H., 1950: A rank-invariant method of linear and polynomial regression analysis. I. Nederl. Akad. Wetensch. Proc., 53, 386-392.

Turner, J., and Coauthors, 2005: Antarctic climate change during the last 50 years. Int. J. Climatol., 25, 279-294, https://doi.org/ 10.1002/joc. 1130 .

Valt, M., and C. Paola, 2013: Climate change in Italian Alps: Analysis of snow precipitation, snow durations and avalanche activity. Proc. 2013 Int. Snow Science Workshop, Grenoble, France, ISSW, 1247-1250.

Vincent, L., X. Zhang, R. Brown, Y. Feng, E. Mekis, E. Milewska, H. Wan, and X. Wang, 2015: Observed trends in Canada's climate and influence of low-frequency variability modes. J. Climate, 28, 4545-4560, https://doi.org/10.1175/JCLI-D-1400697.1.

Viviroli, D., H. H. Dürr, B. Messerli, M. Meybeck, and R. Weingartner, 2007: Mountains of the world, water towers for humanity: Typology, mapping, and global significance. Water Resour. Res., 43, W07447, https://doi.org/10.1029/2006WR005653.

von Storch, H., 1995: Misuses of statistical analysis in climate. Analysis of Climate Variability: Applications of Statistical Techniques, H. von Storch and A. Navarra, Eds., Springer, $11-$ 26, doi:10.1007/978-3-662-03744-7.

Wan, Y.-F., Q.-Z. Gao, Y. Li, X.-B. Qin, Ganjurjav, W.-N. Zhang, X. Ma, and S. Liu, 2014: Change of snow cover and its impact on alpine vegetation in the source regions of large rivers on the Qinghai-Tibetan Plateau, China. Arct. Antarct. Alp. Res., 46, 632-644, https://doi.org/10.1657/1938-4246-46.3.632.

Wang, J., M. Zhang, S. Wang, Z. Ren, Y. Che, F. Qiang, and D. Qu, 2016: Decrease in snowfall/rainfall ratio in the Tibetan Plateau from 1961 to 2013. J. Geogr. Sci., 26, 1277-1288, https:// doi.org/10.1007/s11442-016-1326-8.

Wilcox, R. R., 2010: Fundamentals of Modern Statistical Methods: Substantially Improving Power and Accuracy. Springer, 249 pp.
Willett, K. M., N. P. Gillett, P. D. Jones, and P. W. Thorne, 2007: Attribution of observed surface humidity changes to human influence. Nature, 449, 710-712, https://doi.org/10.1038/ nature 06207.

Xie, P., and P. A. Arkin, 1997: Global precipitation: A 17-year monthly analysis based on gauge observations, satellite estimates, and numerical model outputs. Bull. Amer. Meteor. Soc., 78, 2539-2558, https://doi.org/10.1175/1520-0477(1997) 078<2539:GPAYMA $>2.0$.CO;2.

- J. E. Janowiak, P. A. Arkin, R. Adler, A. Gruber, R. Ferraro, G. J. Huffman, and S. Curtis, 2003: GPCP pentad precipitation analyses: An experimental dataset based on gauge observations and satellite estimates. J. Climate, 16, 2197-2214, https:// doi.org/10.1175/2769.1.

—, R. Adler, G. Huffman, and D. Bolvin, 2011: Global Precipitation Climatology Project-pentad, version 2.2. NOAA National Climatic Data Center, accessed 28 July 2018, https:// data.nodc.noaa.gov/cgi-bin/iso?id=gov.noaa.ncdc:C00933.

Yue, S., and P. Pilon, 2004: A comparison of the power of the $t$ test, Mann-Kendall and bootstrap tests for trend detection. Hydrol. Sci. J., 49, 21-37, https://doi.org/10.1623/hysj.49.1.21.53996. and C. Wang, 2004: The Mann-Kendall test modified by effective sample size to detect trend in serially correlated hydrological series. Water Resour. Manage., 18, 201-218, https:// doi.org/10.1023/B:WARM.0000043140.61082.60.

- P. Pilon, B. Phinney, and G. Cavadias, 2002: The influence of autocorrelation on the ability to detect trend in hydrological series. Hydrol. Processes, 16, 1807-1829, https://doi.org/ 10.1002/hyp.1095.

Zhong, K., F. Zheng, X. Xu, and C. Qin, 2018: Discriminating the precipitation phase based on different temperature thresholds in the Songhua River Basin, China. Atmos. Res., 205, 48-59, https://doi.org/10.1016/j.atmosres.2018.02.002. 